University of Zurich

Department of Economics

Working Paper Series

ISSN 1664-7041 (print)

ISSN 1664-705X (online)

Working Paper No. 322

\title{
Entrepreneurial Finance, Home Equity, and Monetary Policy
}

\author{
Paul Jackson and Florian Madison
}

Revised version, June 2020 


\title{
Entrepreneurial Finance, Home Equity, and Monetary Policy*
}

\author{
Paul Jackson \\ University of California, Irvine
}

\author{
Florian Madison \\ Claremont McKenna College
}

May 1, 2020

\begin{abstract}
We model entrepreneurial finance using a combination of fiat money, credit cards, traditional bank loans, and home equity loans. The banking sector is overthe-counter, where bargaining determines the pass-through from the nominal interest rate to the bank lending rate, characterizing the transmission channel of monetary policy. The strength of this channel depends on the combination of nominal and real assets used to finance investments, and declines in the extent to which housing is accepted as collateral. Optimal investment occurs for a range of positive nominal interest rates due to strategic motives of holding fiat money. An extension shows that said motives vanish with access to competitive financial markets, rendering only the Friedman rule optimal. To address inefficiencies in a high interest rate environment, unconventional policy introducing partially liquid bonds relaxes entrepreneurs' liquidity constraints and restores efficiency.
\end{abstract}

JEL Classification: E22, E40, E52, G31, R31

Keywords: entrepreneurial finance, money, housing, collateral, monetary policy

*We are especially grateful to Guillaume Rocheteau and Aleksander Berensten for their extensive advice and support. Special thanks also go to Randall Wright, Christopher Waller, David Andolfatto, Fernando Martin, Pedro Gomis-Porqueras, Ed Nosal, and Cyril Monnet for our fruitful discussions at the University of Bern and the FRB of St. Louis. Furthermore, we thank the participants of the 2018 Summer Workshop on Money, Banking, Payments and Finance at the FRB of St. Louis, the Fifth Macro Marrakech Workshop at Université Cadi Ayyad, the Economic Theory Reading Group at the University of Basel, the UCI Macro Reading Group, and the participants at the $4^{\text {th }}$ Macro Marrakesh Ph.D. workshop for their comments and thoughtful questions. This paper was previously titled "Corporate Finance, Home Equity, and Monetary Policy". All errors are our own. Emails: paul.jackson922@gmail.com; flomadison@gmail.com. 


\section{Introduction}

This paper provides a monetary search model subject to commitment and bargaining frictions to study entrepreneurial finance in the United States. Capital accumulation can be financed internally using savings and credit card debt, and externally through traditional bank loans and home equity loans, allowing for coexistence of money and credit. The banking sector is over-the-counter, where bilateral bargaining determines the terms of trade, and thus the pass-through from the nominal interest rate to the real lending rate, characterizing the transmission channel of monetary policy.

It is well documented that apart from housing services, home equity is commonly used as collateral to secure loans and lines of credit (HELs and HELOCs) when markets are imperfect. ${ }^{1}$ While a fair share of these loans are used to finance consumption (Greenspan and Kennedy, 2007), they further find high demand among entrepreneurs facing capital expenditures. According to the Annual Survey of Entrepreneurs, in 2016, roughly $6.3 \%$ of all entrepreneurs in the U.S. used home equity loans to start or acquire their business. ${ }^{2}$ The most prominent competing means of financing were savings, traditional banks loans, and credit cards, as summarized in Table 1, characterizing the four main funding channels of entrepreneurs in the United States.

\begin{tabular}{cc}
\hline \hline Funding Source & Relative Frequency \\
\hline Savings & $73.1 \%$ \\
Credit cards & $14 \%$ \\
Traditional bank loans & $16.5 \%$ \\
Home equity loans & $6.3 \%$ \\
\hline
\end{tabular}

Table 1: Entrepreneurs' primary funding sources - Annual Survey of Entrepreneurs (2016)

The limited sources of external funding, as opposed to larger corporations who can issue equity and debt on international financial markets, make entrepreneurs highly susceptible to fluctuations in the housing market and frictions in the local banking sector. Recent data from the Small Business Credit Survey, as summarized in Table 2, shows that in 2017, 22\% of all applicants did not receive a loan at all (extensive margin), while $78 \%$ received some

\footnotetext{
${ }^{1}$ This does not come as a surprise since home equity accounts for nearly $50 \%$ of a household's net wealth and is amongst the most valuable asset an average household holds - Iacoviello (2011).

${ }^{2}$ Furthermore, according to the Survey of Consumer Finances, between 2001 and 2016, $12 \%$ of entrepreneurs financed expenditures through HELs, accounting for a 52\% (74\%) higher average use (amount borrowed) among self-employed relative to households working for someone else.
} 
or all the funding applied for (intensive margin). Our framework incorporates these margins through search frictions and liquidity constraints, where the latter highlights the importance of housing as collateral in the entrepreneurial sector, backing the empirical results by Schmalz et al. (2017) and Corradin and Popov (2015) among others discussed in the related literature.

\begin{tabular}{cc}
\hline \hline Credit application outcomes & All firms \\
\hline All $(100 \%)$ & $46 \%$ \\
Most $(>50 \%)$ & $12 \%$ \\
Some $(<50 \%)$ & $20 \%$ \\
None $(0 \%)$ & $22 \%$ \\
\hline
\end{tabular}

Table 2: Total funding received - Small Business Credit Survey (2017)

Next to the frictions in the banking sector, monetary policy affects the financing landscape of firms. The transmission channel is twofold: directly, through the inflation tax on savings, and indirectly, via the pass-through from nominal interest rates to bank lending rates. Using a monetary search framework, our model allows us to encompass this dimension and provide normative statements with regards to optimal monetary policy.

The baseline environment has an infinite horizon and draws from Rocheteau et al. (2018), extended by a frictionless housing market and unsecured credit card debt. Under uncertainty regarding future investment and financing opportunities, entrepreneurs choose to fund capital expenditures using a combination of internal (fiat money and unsecured credit card debt) and external financing (bank loans). Contrary to the convention in the literature, the banking sector is over-the-counter and terms of the loan contracts are determined by bilateral bargaining between banks and entrepreneurs. ${ }^{3}$ Frictions including a lack of commitment and record keeping make collateral essential for bank loans to be incentive compatible, where a distinction is made between traditional bank loans secured by claims on future profits and home equity loans secured by real estate. The latter makes housing (partially) liquid, adding an additional role next to the consumption of housing services, underpinning its ability to facilitate trade when credit markets are imperfect. Furthermore, the introduction of banks extends the supply of (outside) fiat money by tradeable bank liabilities/ IOUs (inside money), governed by collateral constraints.

Outside money has two roles in our environment. First, it serves as insurance against

\footnotetext{
${ }^{3}$ In doing so, we rely on the observations of Mora (2014), relating the observed dispersion in loan rates to differences in banks' bargaining power.
} 
tightened borrowing constraints in the banking sector, and second, it is used as a strategic device to demonstrate 'skin in the game', allowing entrepreneurs to obtain more favorable terms of trade when bargaining with a bank, generating a multiplier determining the passthrough from the nominal interest rate to the bank lending rate. ${ }^{4}$ As a consequence of this multiplier and the co-existence of money and credit, optimal investment occurs for a positive range of nominal interest rates above the Friedman rule.

Relying on said pass-through and the two roles of outside money, the established model provides novel insights on the transmission of monetary policy. The results show that the magnitude of the real effects following a change in the nominal interest rate depends on the composition of internal and external financing used, and hence the size of the haircuts applied on the provided collateral. If housing is sufficiently pledgeable, the demand for fiat money is low, weakening the transmission channel of monetary policy. If, however, housing is barely accepted as collateral and capital is primarily financed through internal financing and traditional bank loans, the transmission channel is strong. The sensitivity of the passthrough underpins the importance of the individual financing channels and highlights the close relationship between the entrepreneurial sector, the housing market, and monetary policy.

To complement the theoretical results, we provide numerical examples to quantify the effects of a change in the pledgeability of housing on the entrepreneurial sector and the transmission channel of monetary policy. Varying the haircuts on housing allows to account for fluctuations in the housing market and consequential changes in the composition of internal and external finance. For example, at a nominal interest rate of 0.04, increasing the haircut on housing from 0 to 1 causes entrepreneurial investment and output to decrease by $11.7 \%$ and $3.2 \%$, respectively. To quantify the effect of home equity loans on the strength of the transmission channel of monetary policy, we focus on the semi-elasticity of aggregate entrepreneurial investment in response to a change in the nominal interest rate. The calibrated results confirm the aforementioned theoretical outcomes. For example, at a nominal interest rate of 0.04 (as seen in 2007), if housing is denied as collateral, a one percent increase in the nominal interest rate decreases entrepreneurial investment by $8.2 \%$. The larger the share of investments financed by fiat money, i.e., the lower the nominal interest rate, the stronger the

\footnotetext{
${ }^{4}$ The former is in line with Bates et al. (2009), Sánchez and Yurdagul (2013), and Campello (2015) on corporate liquidity management, where fiat money serves as an insurance against the risk of idiosyncratic financing opportunities.
} 
real effects of a change in monetary policy.

With an understanding of the baseline environment, we then use our framework to study the implications of relaxing the frictions faced by entrepreneurs. In a first step, we omit bilateral matching and bargaining and study an environment where entrepreneurs have access to competitive financial markets instead, analogue to competitive capital markets older and larger firms have access to. Relaxing these frictions has direct implications for optimal monetary policy. The most striking result is that the previously obtained positive range of nominal interest rates guaranteeing efficiency collapses for two reasons: First, fiat money does not serve as an insurance against not receiving a bank loan anymore. Second, entrepreneurs have no strategic motive to carry larger money balances to obtain better terms of trade when negotiating with a bank. As a consequence, entrepreneurs only carry sufficient real balances if fiat money is costless to hold and hence, optimality only occurs at the Friedman rule.

In a second step, we study the role of unconventional policy when monetary policy alone can not ensure efficiency. To do this, we extend the baseline model by introducing partially liquid bonds pledgeable as collateral to banks, and with some probability, usable as a means of payment to purchase capital from capital suppliers directly. Bonds expand an entrepreneur's financial wealth, and like fiat money, have a strategic role as they allow entrepreneurs to obtain more favorable terms of trade when accepted by capital suppliers. We show that if the supply of bonds is large enough, entrepreneurs obtain the efficient level of investment regardless of the nominal interest rate. Critically, the optimal supply of bonds depends on the state of the housing market. If there is a negative shock to the supply of housing, or an increase in haircuts, a larger supply of bonds is needed to restore efficiency. Finally, we show that if bonds become more liquid, entrepreneurs rely less on fiat money to finance their investments and are thus able to obtain the optimal level of investment at higher levels of the nominal interest rate, expanding the aforementioned positive range in the baseline model.

\subsection{Related Literature}

This paper is deeply founded in the literature on monetary search-theory and markets with frictions, as surveyed in Rocheteau and Nosal (2017) and Lagos et al. (2017). The first to apply the theoretical toolkit of this literature to study corporate finance and monetary 
policy, and the paper most closely related to ours, were Rocheteau et al. (2018). We build on this framework by tailoring the environment to the entrepreneurial sector in the United States, i.e, introducing credit card debt and a housing market, where real estate has two roles: consumption and saving. The latter allows entrepreneurs to secure bank loans using home equity, capturing the relationship between the housing market, the pass-through from nominal to real rates, and the transmission channel to entrepreneurial investment. ${ }^{5}$ Once established, we then deviate from our baseline model and introduce competitive financial markets and government bonds to study unconventional policy in high interest rate environments, respectively.

Since the Great Recession, a vast literature on the use of home equity to secure bilateral credit transactions emerged, whereas distinction is made between consumption and investment loans. The former are studied by He et al. (2015), incorporating HELs into a Lagos and Wright (2005) environment. The endogenously arising liquidity premium on housing generates dynamics in the value of real estate, explaining parts of the housing boom experienced in the early 2000s. ${ }^{6}$ Using similar toolkits, Branch et al. (2016) provide an application to unemployment by endogenizing the construction sector. Their results show that financial innovations that raise the acceptability of homes as collateral increase house prices and reduce unemployment. Among the first to abstain from consumption loans were Liu et al. (2013), introducing land as collateral in firms' credit constraints using a DSGE model, showing how co-movements of land prices and business investments propagate macroeconomic fluctuations. While the provided results apply for firms of all sizes, a more detailed application to entrepreneurs is provided by Decker (2015). Within a heterogeneous agent DSGE model with housing and entrepreneurship, his results show that while recessions accompanied by a housing crash can explain the decline in entrepreneurial activity experienced in the early 2000s, a broader financial crisis would have no such effects. To further explain the recent synchronization of house prices and entrepreneurial activity, Lim (2018) develops an occupational choice model incorporating home equity loans. His results are in line with Decker (2015) and the paper at hand, showing that a rise in house prices increases entrepreneurial investment. However, a role for monetary policy remains absent. Our paper combines these

\footnotetext{
${ }^{5}$ Another extension to study how heterogeneity of financial frictions and monopolistic competition influences this the transmission channel was provided by Silva (2019).

${ }^{6}$ Complementary results are provided by Justiniano et al. (2015) and Garriga et al. (2019), studying the relationship between the liquidity of real estate and house prices in the United States.
} 
components, allowing for an analysis of entrepreneurial finance, home equity, and monetary policy.

We also draw on empirical work studying the importance of housing as collateral in entrepreneurial finance. Schmalz et al. (2017) found that higher values of collateral increased the likelihood of becoming an entrepreneur and that those with higher values of collateral took on more debt, started larger firms, and were more likely to remain in the long run. Corradin and Popov (2015) in turn focus on real estate prices in the U.S. and found that a $10 \%$ increase in home equity increased the probability of becoming an entrepreneur by 7\% . Adelino et al. (2015) estimated that the collateral lending channel could explain 15-25\% of employment variation in the U.S. between 2002-2012, showing the value of housing as collateral is directly tied to the formation of new businesses. Black et al. (1996) used data from the UK and found that a $10 \%$ increase in the value of home equity increased VAT registrations by nearly 5\%, suggesting that an increase in the value of housing led to more small business formation. Harding and Rosenthal (2017) estimated that a 20\% increase in real home value over two years increased entry into self-employment by 15 percentage points and that self-employed homeowners are more likely to use home equity lines of credit. Abstaining from the value of housing but focusing on its pledgeability, Jensen et al. (2014) found that a reform in Denmark, which increased the availability of home equity loans, increased entry into entrepreneurship.

The rest of this paper is organized as follows. Section 2 introduces the baseline environment. Section 3 solves the dynamic programming problem of the model, laying the foundation for the bargaining game in Section 4 and optimal portfolio choice in Section 5. Monetary policy is discussed in Section 6, followed by numerical examples in Section 7. Extending the baseline model, Section 8 studies an alternative environment involving a competitive banking sector, while Section 9 introduces government bonds into the baseline model to analyze unconventional policy. Last but not least, Section 10 concludes.

\section{Environment}

Time is discrete, continues forever, and each period is divided into two stages, as displayed in Figure 1. In stage 1, two markets open simultaneously. An over-the-counter (OTC) banking 
sector, allowing agents to obtain intra-period bank loans, and a competitive capital market. In stage 2, agents produce and consume a numéraire good, settle outstanding debt obligations, and reallocate their portfolios in a frictionless market.

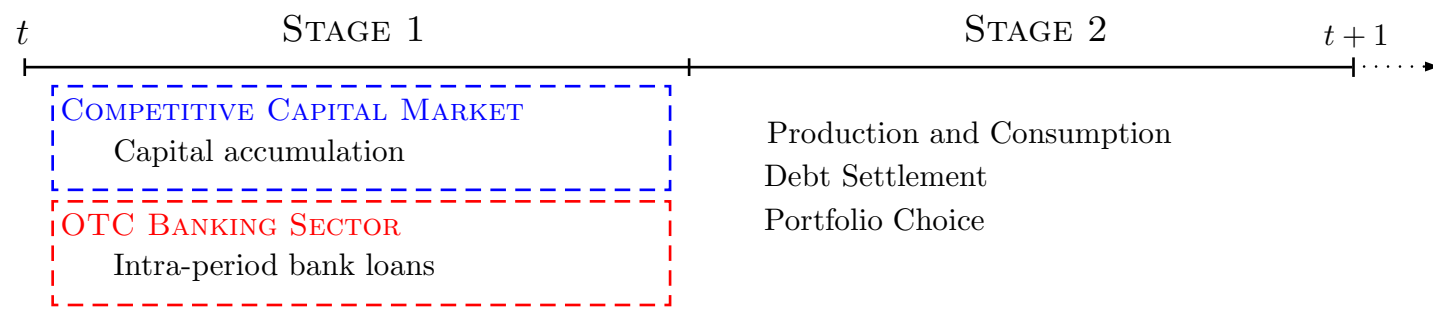

Figure 1: Timing of Events

There are three types of agents, $j \in\{e, s, b\}$ - entrepreneurs, capital suppliers, and banks each in a continuum $[0,1]$, and three types of goods, $\{k, c, a\}$-capital, a consumption good, and housing. Capital, $k$, produced by capital suppliers at unit cost in stage 1 , is used by entrepreneurs as the sole input to produce output, $f(k)$, in units of a numéraire good $c$, in stage 2, where $f^{\prime}(k)>0>f^{\prime \prime}(k)$, with $f(0)=0, f^{\prime}(0)=\infty$, and $f^{\prime}(\infty)=0 \forall k$. At the end of stage 2 both the numéraire good and capital fully depreciate, eliminating gains from storage across periods. Contrary to capital and the numéraire good, housing, $a$, is durable, in fixed supply $A$, and one unit buys $q_{a}$ units of the numéraire good in stage 2. Furthermore, each unit of housing generates one unit of housing services each period, analogue to a Lucas tree. All agents have linear utility over the consumption good, $c$, while only entrepreneurs value housing services, $\vartheta(a)$, where $\vartheta^{\prime}(a)>0>\vartheta^{\prime \prime}(a), \vartheta(0)=0, \vartheta^{\prime}(0)=\infty$, and $\vartheta^{\prime}(\infty)=0 \forall$ a. The discount factor across periods is $\beta=(1+r)^{-1}$ and $r>0$ the rate of time preference, characterizing the entrepreneur's lifetime utility:

$$
\mathbb{E} \sum_{t=0}^{\infty} \beta^{t}\left[c_{t}+\vartheta\left(a_{t}\right)\right]
$$

There is no record keeping of transactions in the competitive capital market and entrepreneurs have limited ability to commit to future actions. Hence, given the timing of events (supplier providing $k$ in stage 1 and entrepreneur producing $c$ in stage 2) and the non-durability of capital and the numéraire good, media of exchange - money and/or credit - are essential for trade to occur. 
We allow for internal and external financing. Internal financing consists of fiat money (savings), $m$, and intra-period credit card debt, $b \in[0, \bar{b}]$, up to an exogenous debt limit $\bar{b}$. There is a central bank managing the supply of fiat money in the economy according to $M^{\prime}=(1+\tau) M$, where $M$ denotes the stock of fiat money in the current period, $M^{\prime}$ the stock in the next period, and expansion/contraction is conducted through lump-sum transfers, $T=\tau M_{t}$. One unit of money can buy $q_{m}$ units of the numéraire good in stage 2 . Since we focus on symmetric and stationary monetary equilibria, it holds that $M^{\prime} / M=q_{m} / q_{m}^{\prime}=\gamma$ with $\gamma$ being the exogenous gross growth rate of the fiat money supply. External financing, on the other hand, can be obtained through banks via intra-period loans, consisting of perfectly divisible and recognizable one-period liabilities (inside money), i.e., banks can commit. ${ }^{7}$ Given the lack of record-keeping and an entrepreneur's limited ability to commit to future actions, bilateral loans need to be collateralized to be incentive compatible. We consider (partial)-pledgeability of housing (HELs), $\rho q_{a} a$, and future output (traditional bank loans), $\chi f(k)$, with $\rho \leq 1$ and $\chi \leq 1 .{ }^{8}$ Hence, expansion and contraction of inside money is bounded by collateral constraints. Settlement of loan obligations, $l$, takes place in stage 2 , where given the banks' ability to commit to future actions, redemption of collateral is guaranteed. In case of default on the part of the entrepreneur, the bank keeps the collateral.

Two idiosyncratic uncertainties determine the composition of internal and external financing: the availability of production/investment opportunities (as in Kiyotaki and Moore (1997)) and the availability of financing opportunities (as in Wasmer and Weil (2004)). With probability $\lambda \in[0,1]$, an entrepreneur encounters an investment opportunity at the beginning of stage 1, guaranteeing access to the production technology $f(k)$ in stage 2 . Once encountered, with probability $\alpha \in[0,1]$, he meets a banker in the OTC banking sector who is willing to provide a loan. Assuming independence, with probability $\lambda \alpha$, an investment opportunity is financed internally and externally, while with probability $\lambda(1-\alpha)$, an investment opportunity is solely financed internally.

At the end of stage 2, entrepreneurs consume the produced numéraire good, $c$, housing services, $\vartheta(a)$, settle outstanding credit obligations, $l \in \mathbb{R}_{+}$and $b \in \mathbb{R}_{+}$, and adjust their portfolio consisting of fiat money and housing, $m$ and $a$.

\footnotetext{
${ }^{7}$ Said liabilities are perfectly recognizable within a period, but can be counterfeited thereafter, which precludes them from circulating across periods.

${ }^{8}$ We assume that housing and future output are pledgeable only to banks, as banks are the only agents who have the technology to verify home-ownership and recover investments. Thus, there is no trade credit between capital suppliers and entrepreneurs.
} 


\section{Model}

An entrepreneur enters stage 2 with $k$ units of capital and financial wealth, $\omega$, denoted in the numéraire consisting of real money balances $q_{m} m$ and housing $q_{a} a$, minus bank and credit card liabilities, $l$ and $b$, to solve:

$$
\begin{aligned}
W^{e}(k, \omega) & =\max _{c, m^{\prime}, a^{\prime}} c+\vartheta(a)+\beta V^{e}\left(m^{\prime}, a^{\prime}\right) \\
\text { s.t. } c & =f(k)+T+\omega-q_{m} m^{\prime}-q_{a} a^{\prime},
\end{aligned}
$$

where $\beta V^{e}\left(m^{\prime}, a^{\prime}\right)$ is the continuation value in stage 1 of the next period. Plugging (3) into (2), yields:

$$
W^{e}(k, \omega)=f(k)+\vartheta(a)+\omega+T+\max _{m^{\prime}, a^{\prime}}\left\{-q_{m} m^{\prime}-q_{a} a^{\prime}+V^{e}\left(m^{\prime}, a^{\prime}\right)\right\}
$$

Hence, since $W^{e}(k, \omega)$ is linear in current wealth, an entrepreneur's choice of fiat money and housing for the subsequent stage $1,\left(m^{\prime}, a^{\prime}\right)$, is independent of current balances $(k, \omega)$. The entrepreneur's value function in stage 1 is:

$$
V^{e}(m, a)=(1-\lambda) W^{e}(0, \omega)+\lambda\left[(1-\alpha) W^{e}\left(k_{I}, \omega\right)+\alpha W^{e}\left(k_{E}, \omega\right)\right]
$$

where capital accumulation is conditional on $\alpha$ and $\lambda$ with $k_{I}$ representing only internally financed capital and $k_{E}$ internally and externally financed capital. Plugging (5) into (4) and updating reduces the portfolio choice in stage 2 to:

$$
\max _{m^{\prime}, a^{\prime}}-\left[q_{m} / \beta-q_{m}^{\prime}\right] m^{\prime}-\left[q_{a} / \beta-q_{a}^{\prime}\right] a^{\prime}+\vartheta\left(a^{\prime}\right)+\lambda\left[(1-\alpha) \Delta_{I}^{e}\left(m^{\prime}, b^{\prime}\right)+\alpha \Delta_{E}^{e}\left(m^{\prime}, a^{\prime}, b^{\prime}\right)\right]
$$

with $\Delta_{I}^{e}(\omega)$ and $\Delta_{E}^{e}(\omega)$ denoting the entrepreneur's surpluses using internal and external financing, respectively. Following perfect competition in the capital market, $\Delta_{I}^{e}(\omega)$ is defined as $\Delta_{I}^{e}(\omega)=f\left(k_{I}\right)-k_{I}$ with $k_{I}=\min \left\{q_{m} m+\bar{b}, k^{*}\right\}$, where $k^{*}$ solves $k^{*} \in \arg \max _{k}[f(k)-k]>$ 0 , analogue to the planner's problem. It represents the entrepreneur's outside option of financing investments with savings and credit card debt only, playing a crucial role when determining $\Delta_{E}^{e}(\omega)$ via bilateral bargaining between a bank and an entrepreneur in Section $4 .^{9}$ Once determined, Section 5 characterizes the entrepreneur's optimal portfolio choice in

\footnotetext{
${ }^{9}$ Savings and credit card debt are used as monetary downpayment to represent 'skin in the game' when negotiating the terms of the loan contract with a bank.
} 
stage 2, paving the way to study optimal policy in Section 6.

Analogue to the entrepreneur, the value functions of a bank and a capital supplier in stage 2 and 1 are:

$$
W^{b, s}(k, \omega)=\max _{m^{\prime}, a^{\prime}} \omega-q_{m} m^{\prime}-q_{a} a^{\prime}+\beta V^{b, s}\left(m^{\prime}, a^{\prime}\right)
$$

and

$$
\begin{aligned}
V^{b}(m, a) & =(1-\lambda) W^{b}(0, \omega)+\lambda\left[(1-\alpha) W^{b}(0, \omega)+\alpha W^{b}(0, \omega+\phi)\right] \\
V^{s}(m, a) & =\max _{k}\left\{-k+W^{s}\left(0, \omega+q_{k} k\right)\right\}
\end{aligned}
$$

where $\phi$ denotes the bank's intra-period loan profits determined via bilateral bargaining in Section 4 and $q_{k} k$ the capital supplier's proceeds from capital sales in stage 1 . The linearity of $W^{s}$ implies $q_{k}=1$, and hence $W^{s}=V^{s}$. Plugging either (8) into (7) or (9) into (7) yields:

$$
\max _{m^{\prime}, a^{\prime}}-\left[q_{m} / \beta-q_{m}^{\prime}\right] m^{\prime}-\left[q_{a} / \beta-q_{a}^{\prime}\right] a^{\prime}
$$

for both banks and capital suppliers. Thus, if the rate of return of money and housing is non-positive, i.e., if $q_{m} / \beta \geq q_{m}^{\prime}$ and $q_{a} / \beta \geq q_{a}^{\prime}$, neither capital suppliers nor banks have an incentive to hold positive positions, and hence $\left(m^{s}, a^{s}\right)=\left(m^{b}, a^{b}\right)=(0,0)$.

\section{Bargaining}

The terms of the loan contract, $\left(k_{E}, \phi, d, y, b\right)$, are determined via proportional bargaining, where $k_{E}$ denotes the total amount of capital financed, $\phi$ the bank's service fee, $y \in[0, a]$ the amount of housing used as collateral, $d \in[0, m]$ the monetary downpayment, and $b \in[0, \bar{b}]$ credit card debt. Let $S=S^{e}+S^{b}$ be the total surplus to be bargained over with:

$$
\begin{aligned}
& S^{e} \equiv W^{e}\left(k_{E}, \omega\right)-W^{e}\left(k_{I}, \omega\right)=f\left(k_{E}\right)-k_{E}-\phi-\Delta_{I}^{e}(\omega), \\
& S^{b} \equiv W^{b}(0, \omega+\phi)-W^{b}(0, \omega)=\phi
\end{aligned}
$$


characterizing the following bargaining problem:

$$
\begin{aligned}
\left(k_{E}, \phi, d, y, b\right) \in \arg \max f\left(k_{E}\right)-k_{E}-\phi-\Delta_{I}^{e}(\omega), \\
\text { s.t. } \theta\left[f\left(k_{E}\right)-k_{E}-\phi-\Delta_{I}^{e}(\omega)\right] \geq(1-\theta) \phi, \\
\text { s.t. } l \equiv k_{E}-q_{m} d-b+\phi \leq \chi f\left(k_{E}\right)+\rho q_{a} y,
\end{aligned}
$$

where $\theta \in[0,1]$ represents the bank's bargaining power, and (14) governs how the total surplus is split proportionally between the bank and the entrepreneur. Equation (15) is the entrepreneur's liquidity constraint and determines the size of the future loan obligation, $l$, where $\rho q_{a} y$ is the collateral value of housing and $\chi f\left(k_{E}\right)$ the collateral value of future output. Debt limits are imposed exogenously following Kiyotaki and Moore (1997) with $\chi(\rho)$ being the fraction of future output (housing) pledgeable to the bank. ${ }^{10}$ It follows immediately that the size of the loan obligation, $l$, decreases with the monetary downpayment, i.e., the amount of capital financed internally using savings and credit card debt, $q_{m} d$ and $b$.

Definition A. An equilibrium of the bargaining game between an entrepreneur and a bank is a pair of strategies, $\left(k_{E}, \phi, d, y, b\right)$, such that the terms of trade, $\left(k_{E}, \phi, d, y, b\right)$, are a solution to the bargaining problem (13)-(15).

If the entrepreneur's liquidity constraint does not bind, the entrepreneur may achieve the socially-efficient level of investment, $k_{E}=k^{*}$. Using (14) and solving for $\phi$ gives:

$$
\phi=\theta\left[f\left(k^{*}\right)-k^{*}-\Delta_{I}^{e}(\omega)\right]
$$

denoting the bank's fraction of the total match surplus. Comparative statics show that $\partial \phi / \partial \Delta_{I}^{e}(\omega)<0$, so the fee collected by the bank is decreasing in the value of the entrepreneur's outside option. Thus, apart from being an insurance against not receiving a bank loan, fiat money incorporates a strategic role in the bargaining game, reducing the bank's surplus. In the limiting case with $\chi=0$ and $\rho=0$ (no bank loan), $k_{E}=k_{I}=k^{*}$ if $q_{m} m+\bar{b} \geq k^{*}$. If, however, $q_{m} m+\bar{b}<k^{*}$, then $k_{I}<k_{E} \leq k^{*}$, where $k_{E} \leq k^{*}$ holds with equality if either output or housing is sufficiently pledgeable. Plugging (16) into (15), we

\footnotetext{
${ }^{10}$ One can interpret $\rho$ as a loan-to-value ratio representing various transaction costs and information asymmetries regarding the resale value of a house, and $\chi$ as the parts of the capital input a bank can recover in case the entrepreneur defaults on his credit obligation (scrap value).
} 


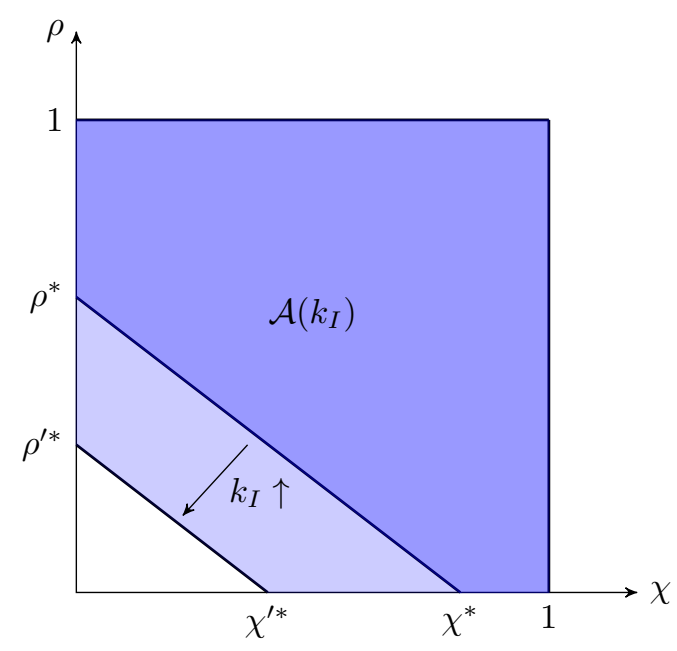

Figure 2: Set $\mathcal{A}\left(k_{I}\right)$ in an Unconstrained Equilibrium

characterize a set of pairs, $(\hat{\chi}, \hat{\rho})$, such that $k_{E}=k^{*}$ :

$$
\mathcal{A}\left(k_{I}\right)=\left\{(\hat{\chi}, \hat{\rho}) \in \mathbb{R}_{+}^{2}: \hat{\chi} f\left(k^{*}\right)+\hat{\rho} q_{a} y \geq \theta\left[f\left(k^{*}\right)-f\left(k_{I}\right)\right]+(1-\theta)\left(k^{*}-k_{I}\right)\right\},
$$

with the threshold values $\hat{\chi} \leq 1$ and $\hat{\rho} \leq 1$. From (17), $\hat{\chi}$ is decreasing in $\rho$ and $\hat{\chi} \rightarrow 0$ as $\rho \rightarrow \rho^{*}$, where $\rho^{*}$ allows entrepreneurs to accumulate $k^{*}$ when $\chi=0$ (analogue for $\chi^{*}$ ). The same, but vice versa, holds for $\hat{\rho}$. Furthermore, with an increase in $k_{I}, \mathcal{A}\left(k_{I}\right)$ converges towards the origin, since there are more combinations of $\chi$ and $\rho$ that allow for $k_{E}=k^{*}$. Figure 2 illustrates.

Consider now the case where the entrepreneur's liquidity constraint is binding. Solving (14) for $\phi$ and substituting into (15) with $d=m, y=a$, and $b=\bar{b}$ gives:

$$
(1-\theta) k_{E}+\theta\left[f\left(k_{E}\right)-\Delta_{I}^{e}(\omega)\right]=\chi f\left(k_{E}\right)+\rho q_{a} a+q_{m} m+\bar{b},
$$

which determines $k_{E}$. The corresponding comparative statics show that $\partial k_{E} / \partial \theta<0$, $\partial k_{E} / \partial k_{I}>0, \partial k_{E} / \partial q_{a} a>0, \partial k_{E} / \partial \rho>0$, and $\partial k_{E} / \partial \chi>0$. Lemma A summarizes.

Lemma A. There exists a unique solution to (13) with $k_{I} \in \min \left\{q_{m} m+\bar{b}, k^{*}\right\}$. If $\chi<\chi^{*}$ and $\rho<\rho^{*}$, there exists an $m^{*}$ such that $k^{*}>q_{m} m^{*}+\bar{b}$ and the following is true: If $m \geq m^{*}$, 
the solution to (13) is:

$$
\begin{aligned}
k_{E} & =k^{*}, \\
\phi & =\theta\left[f\left(k^{*}\right)-k^{*}-\Delta_{I}^{e}(\omega)\right] .
\end{aligned}
$$

If $m<m^{*}$, however, then $\left(\phi, k_{E}\right)$ solves:

$$
\begin{aligned}
\phi & =\theta\left[f\left(k_{E}\right)-k_{E}-\Delta_{I}^{e}(\omega)\right], \\
\theta\left[f\left(k_{E}\right)-k_{E}-\Delta_{I}^{e}(\omega)\right] & =\chi f\left(k_{E}\right)+\rho q_{a} a-k_{E}+k_{I},
\end{aligned}
$$

and $k_{E} \geq \underline{k}_{E}$, where $\chi f^{\prime}\left(\underline{k}_{E}\right)=1$. Proof in Appendix A.

It is important to note that in equilibrium $\partial\left[k_{I}+\chi f\left(k_{E}\right)+\rho q_{a} a\right] / \partial k_{I}>1$, and thus by carrying an additional unit of fiat money along the period, entrepreneurs can increase their accumulated capital by more than one unit. The intuition behind this result is straightforward. An additional unit of fiat money does not only buy the entrepreneur more capital from the supplier, but also signalizes a higher investment to the bank, enabling the entrepreneur to credibly pledge more future output. Lemma B revisits this result and determines its implications for the bank lending rate.

Lemma B. The bank lending rate, $r^{b}$, defined as the ratio of the fee, $\phi$, to the loan size, $k_{E}-k_{I}$, is given by:

$$
r^{b}=\frac{\phi}{k_{E}-k_{I}}= \begin{cases}\frac{\theta\left[f\left(k^{*}\right)-k^{*}-\Delta_{I}^{e}(\omega)\right]}{k^{*}-k_{I}} & \text { if } m \geq m^{*}, \\ \frac{\theta\left[f\left(k_{E}\right)-k_{E}-\Delta_{I}^{e}(\omega)\right]}{k_{E}-k_{I}} & \text { if } m<m^{*},\end{cases}
$$

where, given $q_{m}, \chi$ and $\rho, m^{*}$ is the minimal amount of fiat money the entrepreneur needs to attain $k^{*}$ through bank credit. Proof in Appendix B.

From Lemma B and Figure 3, the bank lending rate is decreasing in $k_{I}$, as the entrepreneur faces a more valuable outside option, $\Delta_{I}^{e}(\omega)$. Hence, the more fiat money an entrepreneur is able to bring into stage 1, i.e., the more capital is financed internally, the lower the real lending rate, $\partial r^{b} / \partial k_{I}<0$. This pass-through is revisited in more detail in Sections 6 and 7 . 


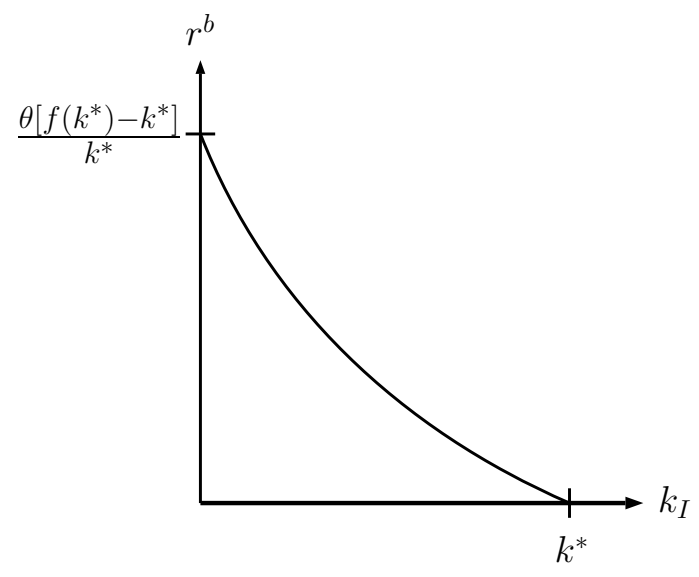

Figure 3: Bank Lending Rate

\section{Portfolio Choice}

To determine the entrepreneur's optimal portfolio choice in stage 2, we revisit (6):

$$
\max _{m^{\prime}, a^{\prime}}-\left[q_{m} / \beta-q_{m}^{\prime}\right] m^{\prime}-\left[q_{a} / \beta-q_{a}^{\prime}\right] a^{\prime}+\vartheta\left(a^{\prime}\right)+\lambda\left[(1-\alpha) \Delta_{I}^{e}\left(\omega^{\prime}\right)+\alpha \Delta_{E}^{e}\left(\omega^{\prime}\right)\right]
$$

with:

$$
\begin{aligned}
& \Delta_{I}^{e}(\omega)=\left\{\begin{array}{l}
f\left(k^{*}\right)-k^{*} \quad \text { if } k_{I} \geq k^{*} \\
f\left(k_{I}\right)-k_{I} \quad \text { if } k_{I}<k^{*},
\end{array}\right. \\
& \Delta_{E}^{e}(\omega)= \begin{cases}(1-\theta)\left[f\left(k^{*}\right)-k^{*}\right]+\theta \Delta_{I}^{e}(\omega) & \text { if } m \geq m^{*} \\
(1-\chi) f\left(k_{E}\right)-\rho q_{a} a-k_{I} & \text { if } m<m^{*},\end{cases}
\end{aligned}
$$

where the terms of trade are a function of the entrepreneur's wealth. The first term, $-\left[q_{m} / \beta-q_{m}^{\prime}\right] m^{\prime}$, represents the opportunity costs of carrying fiat money across the period, while $-\left[q_{a} / \beta-q_{a}^{\prime}\right] a^{\prime}$ is the cost of holding real estate.

Definition B. An equilibrium in stage 2 is a list of portfolios, terms of trade in stage 1, and aggregate balances, $\left\{[m(\cdot), a(\cdot)],\left[k_{I}(\cdot), k_{E}(\cdot), \phi(\cdot), d(\cdot), y(\cdot), b(\cdot)\right], M, A\right\}$, such that:

(i) $[m, a]$ is a solution to (24);

(ii) $k_{I}=\min \left\{q_{m} m+\bar{b}, k^{*}\right\}$;

(iii) $\left[k_{E}, \phi, d, y, b\right]$ is a solution to $(13)$; 
(iv) $M^{\prime}=(1+\tau) M$ is the law of motion of the fiat money stock;

(v) A is the total supply of housing in the economy; and

(vi) Market clearing conditions, $\int_{0}^{1} a(j) d j=A$ and $\int_{0}^{1} m(j) d j=M$, hold.

Lemma C. There exists a unique solution to (24):

$$
\begin{aligned}
q_{m} & =\beta q_{m}^{\prime}\left[1+\mathcal{L}_{m}\right], \\
q_{a} & =\beta\left[q_{a}^{\prime}\left(1+\mathcal{L}_{a}\right)+\vartheta^{\prime}(a)\right],
\end{aligned}
$$

with $\left(\mathcal{L}_{m}, \mathcal{L}_{a}\right)=(0,0)$ for $k_{I}=k^{*}$, and:

$$
\begin{aligned}
& \mathcal{L}_{m}=\left\{\begin{array}{cl}
\lambda[1-\alpha(1-\theta)]\left[f^{\prime}\left(k_{I}\right)-1\right] & \text { for } k_{E} \geq k^{*}, \\
\lambda \alpha\left[\frac{(1-\chi) f^{\prime}\left(k_{E}\right)\left[1+\theta\left(f^{\prime}\left(k_{I}\right)-1\right)\right]}{(1-\theta)-(\chi-\theta) f^{\prime}\left(k_{E}\right)}-1\right]+\lambda(1-\alpha)\left[f^{\prime}\left(k_{I}\right)-1\right] & \text { for } k_{E}<k^{*},
\end{array}\right. \\
& \mathcal{L}_{a}=\left\{\begin{array}{cl}
0 & \text { for } k_{E} \geq k^{*}, \\
\lambda \alpha \rho\left[\frac{(1-\chi) f^{\prime}\left(k_{E}\right)}{1-\theta-(\chi-\theta) f^{\prime}\left(k_{E}\right)}-1\right] & \text { for } k_{E}<k^{*},
\end{array}\right.
\end{aligned}
$$

where $\mathcal{L}_{m}$ and $\mathcal{L}_{a}$ correspond to the liquidity premia of money and housing, respectively. Proof in Appendix $C$.

Consider the three cases from the bargaining game in Section $4: k_{I} \geq k^{*}, k_{E} \geq k^{*}$, and $k_{E}<k^{*}$. If money is costless to hold, i.e., $\mathcal{L}_{m}=0$, an entrepreneur obtains enough fiat money to purchase $k_{I}=k^{*}$. As a consequence, housing is priced at its fundamental value with $\mathcal{L}_{a}=$ 0 . If $\mathcal{L}_{m}>0$, however, money is costly to hold and $k_{I}<k^{*}$. As a result, there is demand for external finance. Two cases need to be considered: If the entrepreneur's liquidity constraint, (15), is non-binding, then $k_{E} \geq k^{*}$. Nonetheless, fiat money incorporates a positive liquidity premium, $\mathcal{L}_{m}>0$, since an additional unit would increase the entrepreneur's outside option, $\Delta_{I}^{e}(\omega)$, and hence decrease the cost of borrowing from a bank. Housing, however, still trades at the fundamental value, i.e., $\mathcal{L}_{a}=0$, since the entrepreneur is not constrained in the amount of collateral carried into stage 1 . If (15) is binding, however, then $k_{E}<k^{*}$, and thus $\mathcal{L}_{a}>0$, since an additional unit of housing would relax (15). The costlier fiat money, the larger the premium. 

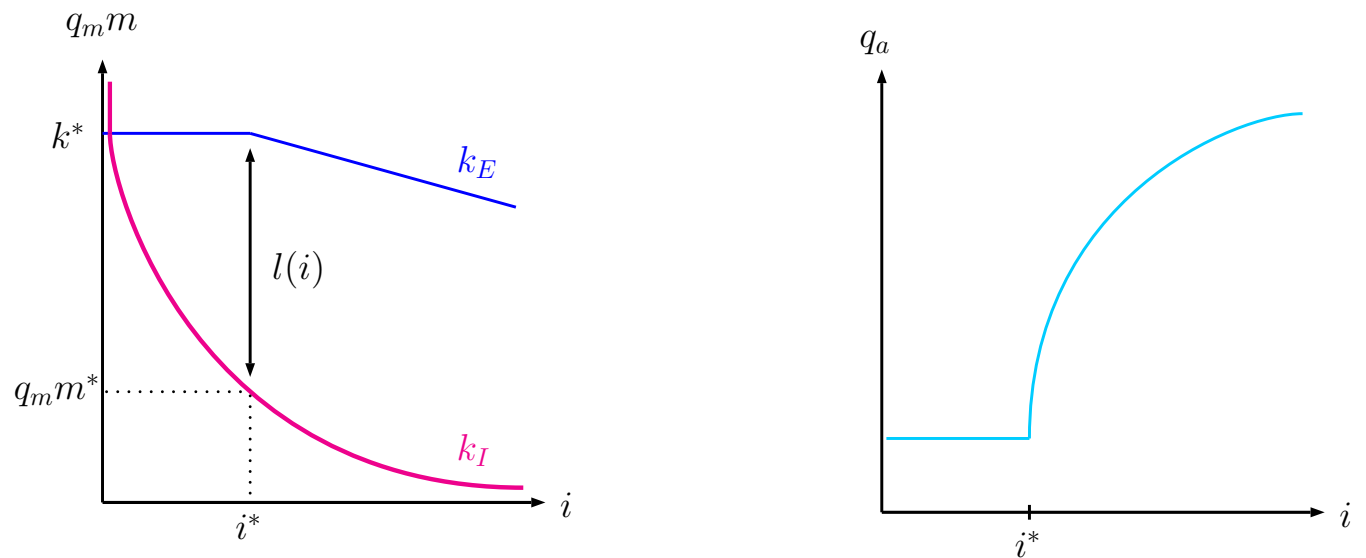

Figure 4: Money and Housing Demand

\section{Monetary Policy and the Transmission Mechanism}

Having determined the bargaining game and the general equilibrium results of the model, this section studies optimal monetary policy. We start by characterizing the nominal interest rate, followed by an analysis of the pass-through to understand how changes in monetary policy affect the terms of trade in the banking sector. Last but not least, we then analyze the transmission of monetary policy to aggregate investment and lending.

Proposition A. (Nominal Interest Rate) Define the nominal interest rate as $i=\gamma / \beta-1$ and $i^{*}$, where $i^{*}$ corresponds to $m=m^{*}$. If $i=0$ (the Friedman rule), then $k_{I}=k_{E}=k^{*}$. If $0<i \leq i^{*}$, then $k_{I}<k_{E}=k^{*}$. If $i>i^{*}$, then $k_{E}<k^{*}$. Comparative statics involve $\partial i^{*} / \partial \rho>0$ and $\partial i^{*} / \partial \chi>0$. Proof in Appendix D.

Proposition A characterizes optimal monetary policy using the general equilibrium results in Section 5, as visually represented in Figure 4. The results show that optimal investment occurs for a positive range of nominal interest rates, $0<i \leq i^{*}$, due to the strategic role of fiat money in the bargaining process. Hence, even if money is costly to carry along the period, the benefits of bringing an additional unit to the negotiations with a bank outweigh the inflation tax, where comparative statics show that an increase in the pledgeability of housing or future output, $\rho$ and $\chi$, increases $i^{*}$. At the Friedman rule, $i=0$, however, banks have no role and first-best investment is entirely financed internally.

In order to study the pass-through from the nominal interest rate, $i$, to the bank lend- 
ing rate, $r^{b}$, we rely on first-order Taylor approximations. Distinction is made between an unconstrained and a constrained equilibrium. In an unconstrained equilibrium, we use a first-order approximation of the equilibrium for $i$ close to 0 , and hence $k_{I}$ close to $k^{*}$. We take this approach for two reasons. First, if $i \approx 0$, then $k_{I}<k^{*}$, and thus bank credit is essential. Second, it allows for closed form solutions. To analyze a constrained equilibrium and maintain analytical tractability, we set $\theta=0$ and take a first-order approximation of an equilibrium where $i \approx i^{*}$ and thus $k_{E} \approx k^{*}$. While setting the bank's bargaining power to zero implies $r^{b}=0$, we are still able to derive closed form approximations for $k_{I}$ and $k_{E}$. A more general analysis with $\theta>0$ is provided in Section 7. With this in mind, Proposition B summarizes.

Proposition B. (Pass-Through) For $i \approx 0$, the pass-through of the nominal interest rate to the bank lending rate is approximated by:

$$
r^{b} \approx \frac{\theta i}{2 \lambda[1-\alpha(1-\theta)]}
$$

For $i \approx i^{*}$, however, $r^{b}=0$ since $\theta=0$. Comparative statics involve $\partial r^{b} / \partial \lambda<0, \partial r^{b} / \partial \theta>0$, and $\partial r^{b} / \partial \alpha>0$. Proof in Appendix E.

For $i \approx 0$, equation (30) identifies a positive pass-through from the nominal interest rate to the bank lending rate, $\partial r^{b} / \partial i>0$, since entrepreneurs rely more on external finance. For $i \approx i^{*}$, however, the pass-through cannot be characterized, since we set $\theta=0$ for analytical tractability. Further comparative statics show that an increase in $\lambda$ weakens the pass-through from the nominal interest to the bank lending rate, while an increase in $\theta$ or $\alpha$ strengthens the pass-through. Moreover, a change in $\rho$ or $\chi$ has no effect on the pass-through.

With this understanding, we proceed to analyze the transmission of monetary policy to aggregate investment and lending, $K \equiv \lambda\left[(1-\alpha) k_{I}+\alpha k_{E}\right]$ and $L \equiv \lambda \alpha\left(k_{E}-k_{I}\right)$. Let $\tilde{k}=k^{*}-\chi f\left(k^{*}\right)-\frac{\rho a \beta \vartheta^{\prime}(a)}{1-\beta}$ and $i^{*}=\lambda(1-\alpha)\left[f^{\prime}(\tilde{k})-1\right]$, where $\tilde{k}$ is defined as the minimum $k_{I}$ an entrepreneur needs to obtain $k_{E}=k^{*}$, and $i^{*}$ is the corresponding nominal interest rate. 
For $i \approx 0$ and thus $k_{E} \approx k^{*}$, the transmission channel is approximated by: ${ }^{11}$

$$
\begin{aligned}
& K \approx \lambda k^{*}+\frac{(1-\alpha) i}{f^{\prime \prime}\left(k^{*}\right)[1-\alpha(1-\theta)]} \\
& L \approx \frac{-\alpha i}{f^{\prime \prime}\left(k^{*}\right)[1-\alpha(1-\theta)]}
\end{aligned}
$$

For $i-i^{*} \approx 0$ and $\theta=0$, however,

$$
\begin{aligned}
k_{E}-k^{*} & \approx \frac{k_{I}-\tilde{k}}{1-\mathcal{O}} \approx-\frac{i-i^{*}}{D}, \\
L & \approx \lambda \alpha\left[k^{*}-\tilde{k}-\frac{\mathcal{O}\left(i-i^{*}\right)}{D}\right],
\end{aligned}
$$

where $D>0$, and:

$$
\mathcal{O}=\chi+\left(\frac{\beta \rho}{1-\beta}\right)^{2}\left[\frac{\alpha \lambda a \vartheta^{\prime}(a) f^{\prime \prime}\left(k^{*}\right)}{1-\chi}\right] .
$$

Proposition C summarizes the transmission mechanism.

Proposition C. (Transmission Mechanism) For $\theta=0, \chi<\chi^{*}$, and $\rho<\rho^{*}$, transmission of monetary policy to aggregate investment and lending is characterized by the following three regions:

$$
\begin{gathered}
A: i \leq i^{*} \text { with } \partial k_{I} / \partial i<\partial k_{E} / \partial i=0, \quad \text { and } \partial L / \partial i>0, \\
B: i>i^{*} \text { with } \partial k_{I} / \partial i<\partial k_{E} / \partial i<0, \quad \text { and } \partial L / \partial i>0 \\
C: i>i^{*} \quad \text { with } \partial k_{E} / \partial i<\partial k_{I} / \partial i<0, \quad \text { and } \partial L / \partial i<0
\end{gathered}
$$

as represented in Figure 5 and equations (31)-(35). Comparative statics show:

$$
\begin{array}{lll}
\partial\left|\partial k_{E} / \partial i\right| / \partial \rho=0 & \text { for } & i \leq i^{*} \\
\partial\left|\partial k_{E} / \partial i\right| / \partial \rho<0 & \text { for } & i>i^{*} .
\end{array}
$$

Proof in Appendix F.

Proposition $\mathrm{C}$ analyzes the effect of a change in the nominal interest rate on aggregate investment and lending, characterizing three distinct regions. In region $A, i \leq i^{*}$, and thus the entrepreneur's liquidity constraint, (15), does not bind. As a consequence, $k_{I}$ decreases with an increase in $i$, while $k_{E}$ remains unaffected. From (32), aggregate lending

${ }^{11}$ Details of the derivation can be found in Appendix $\mathrm{N}$. 


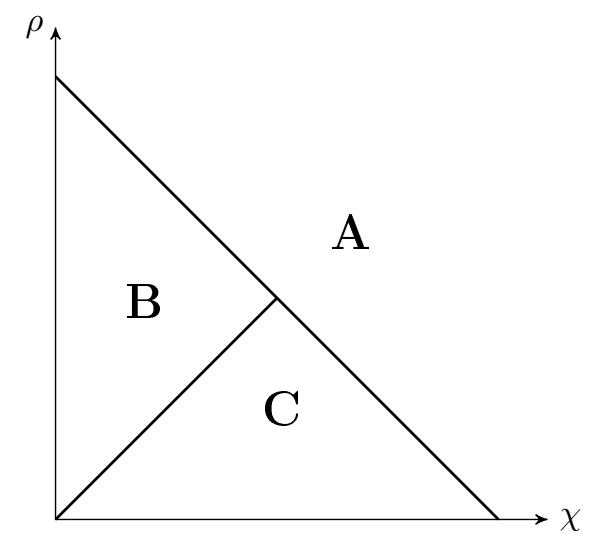

Figure 5: Transmission to aggregate investment and lending

is increasing in $i$, as entrepreneurs rely more on external finance. For $i>i^{*}$, however, an increase in $i$ decreases both internally and externally financed capital. Given (33) and (35), the strength of this effect depends on the composition, i.e., the combination of savings, credit card debt, traditional bank loans, and HELs used to purchase $k_{E}$. The effect on aggregate lending, i.e., $\partial L / \partial i$, follows this outcome. Consider first region $B$, in which an entrepreneur relies extensively on HELs. In this scenario, $k_{I}$ will decrease more than $k_{E}$ in response to an increase in $i$, as entrepreneurs successfully hedge against inflation by using their real asset (housing) when bargaining with the bank. The increased demand for housing and the consequential price appreciation increases $L$ and weakens the transmission channel of monetary policy. In contrast, in region $C$, an increase in the nominal interest rate, $i$, decreases $k_{E}$ more than $k_{I}$, implying a decrease in aggregate lending, $L$. Thus, whenever the pledgeability of housing is limited, entrepreneurs are unable to alleviate the inflation tax and as a result, the appreciation in house prices does not compensate for the reduction in real money balances and the consequentially worse terms of trade when bargaining with a bank. Further, comparative statics show that for region $B$ and $C$, an increase in $\rho$ weakens the transmission mechanism, while in region $A$, a change in $\rho$ has no effect on $\left|\partial k_{E} / \partial i\right|$.

\section{$7 \quad$ Numerical examples}

Having characterized the transmission channel analytically, we now complement the previous results with numerical examples to quantify the channels discussed to this point. The 
key difference to the previous Taylor approximations is that we allow banks to have a positive bargaining power, $\theta>0$, enabling an analysis of the pass-through in a constrained equilibrium.

To discipline the examples, we calibrate the model to U.S. data covering 2000-2016. ${ }^{12}$ We start by setting the discount factor to $\beta=0.97$. Our measure for the nominal interest rate is the 3-month T-bill secondary market rate with an average of $i=0.0163$. The probability to have a bank loan approved, $\alpha$, is 0.80 following the 2003 Survey of Small Business Finances. The pledgeability of future output is calculated as the average ratio of liabilities to assets among small businesses. From the Federal Reserve Flow of Funds Accounts, we calculate $\chi=0.24$. The pledgeability of housing, $\rho$, is set equal to the average ratio of home equity loan limits to the average sale price of U.S. homes between 2006 and 2016. Using data from the Federal Reserve Bank of New York's Quarterly Report on Household Debt and Credit and the FRED database, we find $\rho=0.18$. We then choose $\bar{b}$ to match the average ratio of credit card limits to home equity loan limits and find $\bar{b}=0.3783 .^{13}$ We estimate the probability of receiving an investment opportunity, $\lambda$, by calculating the average percentage of entrepreneurs who started their business within the last year. Using data from the Survey of Consumer Finances (SCF) between 2001 and 2016, we estimate $\lambda=0.0628$. To pin down $\theta$, we follow Rocheteau et al. (2018) in targeting the spread between the prime bank rate and the 3-month T-bill rate of 3.25\%, i.e. $r^{b}-i=0.0325 .{ }^{14}$ Last but not least, we define the functional forms for the entrepreneur's production function, $f(k)=\nu k^{\eta}$, and the utility of housing services, $\vartheta(a)=a^{1 / 2}$, where $\nu=\beta /(1-\beta)$ is a scaling parameter. ${ }^{15}$

Figure 6 illustrates the effect of a change in the pledgeability of housing on aggregate investment, lending, and output at difference levels of the nominal interest rate. Panel (a) shows that aggregate investment is increasing in $\rho$ until an entrepreneur is able to obtain $k^{*}$ through external finance. As the nominal interest rate increases, a larger value of $\rho$ is required to obtain $k^{*}$. For example, an increase of the nominal interest rate from $i=0.04$ to $i=0.06$ requires $\rho$ to increase from 0.35 to 0.55 to ensure the entrepreneur can still obtain

\footnotetext{
${ }^{12}$ See Appendix $M$ for details on data sources and calculations.

${ }^{13}$ Using data from the Federal Reserve Bank of New York's Quarterly Report on Household Debt and Credit we find the average ratio of credit card limits to home equity loan limits, between 2003-2016, to be 0.13 .

${ }^{14}$ For $0<i<i^{*}, r^{b}$ is given by equation (23) for the case of $m>m^{*}$. We check that under the parameters in Table 3 , an entrepreneur's liquidity constraint does not bind for $i<0.0308$.

${ }^{15}$ Recall that the fundamental value of housing is $q_{a}=\beta \vartheta^{\prime}(A) / 1-\beta$. Without scaling the production function, say if $f(k)=k^{\eta}$, entrepreneurs would mechanically be able to obtain $k^{*}$ through bank loans (as $f^{\prime}\left(k^{*}\right)=1$ ) for $\rho>0$.
} 


\begin{tabular}{clcc}
\hline Parameter & Definition & Value & Target \\
\hline$\beta$ & Discount factor & 0.97 & Annual frequency \\
$i$ & Nominal interest rate & 0.0163 & 3 -month T-bill rate \\
$\alpha$ & Probability of receiving bank credit & 0.80 & Loan acceptance rate \\
$\lambda$ & Probability of receiving an investment opportunity & 0.0628 & Formation of new businesses \\
$\theta$ & Bank's bargaining power & 0.162 & Spread \\
$\chi$ & Fraction of future output that is pledgeable & 0.24 & Asset-to-liability ratio \\
$\rho$ & Fraction of housing that is pledgeable & 0.18 & HE limit-to-home price ratio \\
$\bar{b}$ & Maximum amount of unsecured credit & 0.3783 & Credit card limit-to-HE limit ratio \\
$\eta$ & Capital share & $1 / 3$ & Fixed \\
\hline
\end{tabular}

Table 3: Parameter values

$k_{E}=k^{*}$. Panel (a) also illustrates that, at $i=0.04$, a crash in the housing market that causes $\rho$ to decrease from 1 to 0 causes aggregate investment to decrease by $11.7 \%$.

Panel (b) shows the effect of a change in $\rho$ on aggregate lending. As $\rho$ increases and entrepreneurs rely more on external finance, aggregate lending increases. For example, at $i=0.04$, an increase in $\rho$ from 0 to 1 increases aggregate lending by $27.6 \%$. Panel (c) depicts the effect of $\rho$ on aggregate output and shows very similar patterns to those seen in panel (a), as aggregate output is increasing in aggregate investment. At $i=0.04$, a decline in $\rho$ from 1 to 0 causes aggregate output to decrease by $3.2 \%$, demonstrating that a crash in the acceptability of housing as collateral can have a significant impact on the entrepreneurial sector. Panel (c) also shows that the decline in output following such a crash depends on the state of monetary policy. At $i=0.08$, the same change in $\rho$ causes aggregate output to decrease by $9.1 \%$. We now turn to emphasize this point further in quantifying the transmission of monetary policy.

To study the transmission mechanism of monetary policy, we focus on the pass-through rate, $\partial r_{b} / \partial i$, and the semi-elasticity of aggregate investment and aggregate lending, i.e., the percentage change in response to a one percentage point increase in the nominal interest rate, $\partial \log (K) / \partial i$, and $\partial \log (L) / \partial i$. By varying the pledgeability of housing, $\rho$, between 0 and 1, we account for changes in the composition of financing. We focus on these effects for $i \in[0,0.12]$, whereas the calibration determines $i^{*}=0.0308$.

Starting with the pass-through from the nominal interest rate to the bank lending rate, Figure 7 displays a positive pass-through rate, $\partial r^{b} / \partial i$, for all values of $\rho$, where $\left|\partial r^{b} / \partial i\right| / \partial \rho<$ 0. Hence, an increase in the pledgeability of housing dampens the pass-through rate, confirming the theoretical results in Proposition C. For example, at $i=0.04$, a decrease in $\rho$ from 


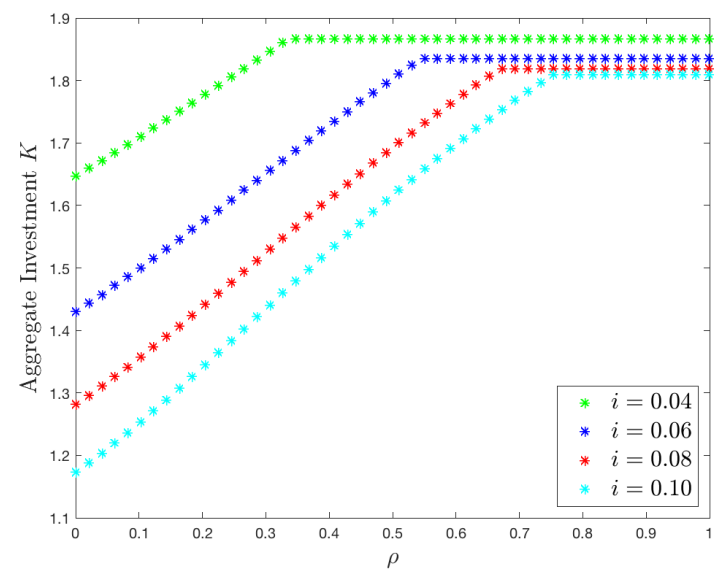

(a) Aggregate investment

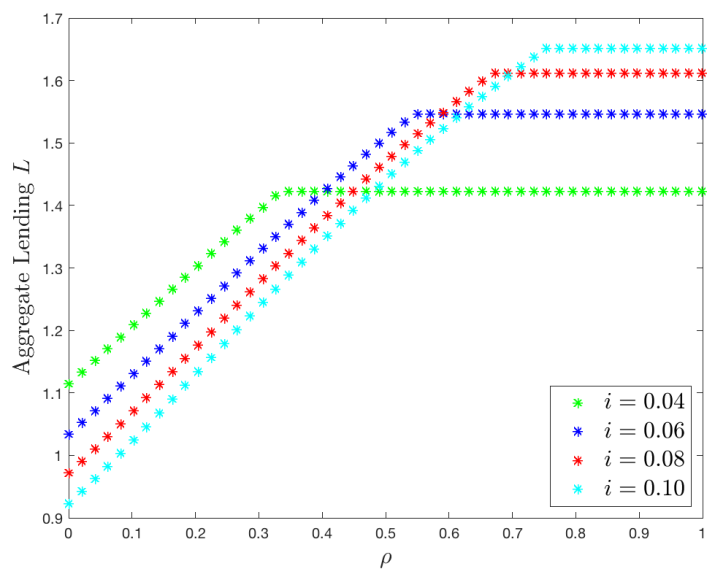

(b) Aggregate lending

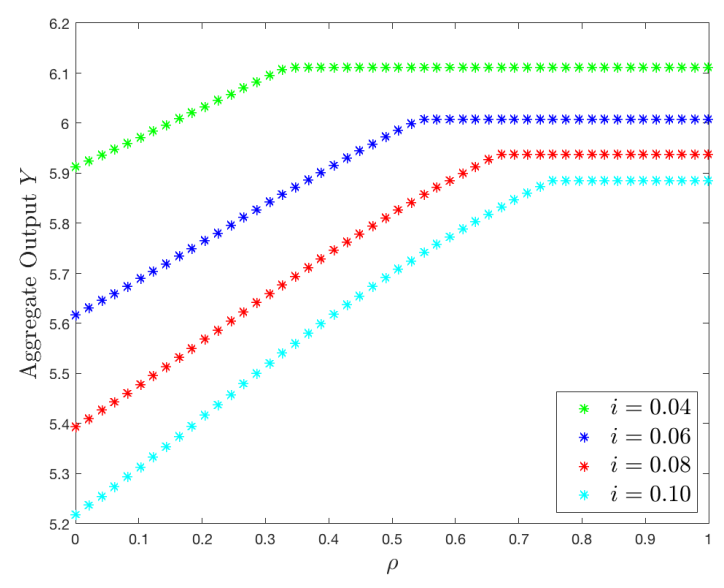

(c) Aggregate output

Figure 6: The pledgeability of housing aggregate outcomes

0.2 to 0 increases the pass-through rate from 1.71 to 1.85 , an increase of $8.1 \%$, illustrating the sensitivity of the pass-through to the pledgeability of housing.

Focusing now on the transmission to aggregate investment and lending, Figure 8 presents our results. Panel (a) shows the semi-elasticity of aggregate investment as the pledgeability of housing varies from 0 to 1 . From Proposition $\mathrm{C}$ we know that $\partial \log (K) / \partial i<0$, whereas the magnitude depends on whether the entrepreneur faces a binding liquidity constraint or not. The calibrated results confirm and show that for $i \leq 0.022$, the equilibrium is unconstrained for any $\rho \in[0,1]$, and hence the semi-elasticity independent of $\rho$, since $\partial k_{I} / \partial i<\partial k_{E} / \partial i=0$ for $i \leq i^{*}$. For $i>i^{*}$, however, the liquidity constraint binds, $\partial k_{E} / \partial i<0$, and thus $\partial \log (K) / \partial i$ depends on $\rho$. When $\rho$ is lower, the semi-elasticity is larger, and thus the 


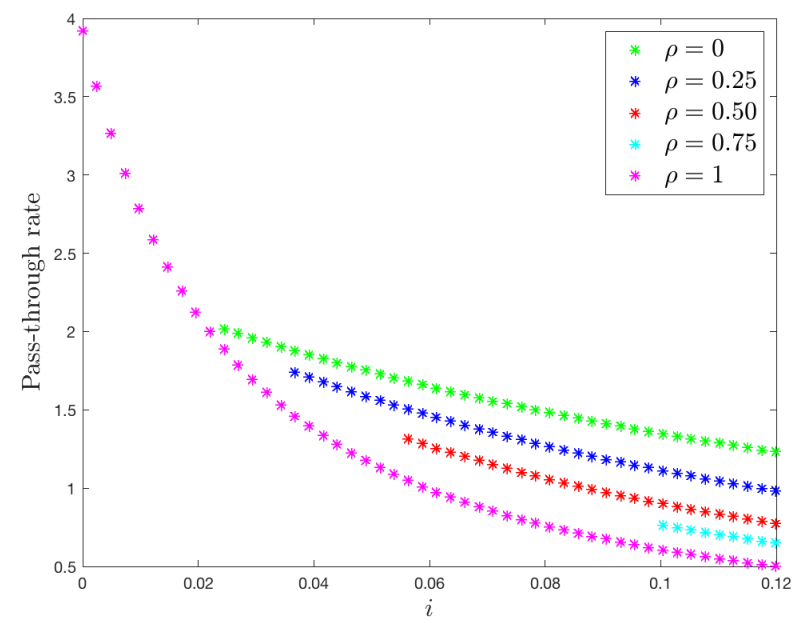

Figure 7: The pass-through of monetary policy

stronger the transmission channel. For example, at $i=0.04$, the semi-elasticity varies from -8.19 to -6.84 as $\rho$ varies from 0 to 0.2 . In the limiting case with $\rho=1, \partial \log (K) / \partial i$ is close to zero and monetary policy has relatively little impact on entrepreneurial investment.

Panel (b) in turn focuses on the semi-elasticity of aggregate lending, $\partial \log (L) / \partial i$. The results show that the semi-elasticity is positive in case of a non-binding liquidity constraint and negative if the liquidity constraint binds, where $|\partial L / \partial i| / \partial \rho<0 .{ }^{16}$ Thus, for most values of the nominal interest rate over the sample period, the response of aggregate lending is strictly negative, even for large values of $\rho$ (region $C$ in Proposition $\mathrm{C}$ ).

Finally, panel (c) shows that the semi-elasticity of aggregate output, $\partial \log (Y) / \partial i$, follows the same pattern as the semi-elasticity of aggregate investment and that monetary policy has a larger impact on aggregate output when $\rho$ is small and the entrepreneur's liquidity constraint is binding. To illustrate, suppose again that $i=0.04$. The semi-elasticity of output varies from -1.07 when $\rho=1$ to -2.95 when $\rho=0$, which further illustrates that monetary policy can have a much more profound impact on economic activity in the entrepreneurial sector when housing can not be used to secure financing.

\footnotetext{
${ }^{16}$ The values of $\partial \log L / \partial i$ for low values of $i$ do not appear on the graph because they approach $\infty$ as $i \rightarrow 0$ (as $L=0$ when $i=0$ and $k_{I}=k^{*}$ ).
} 


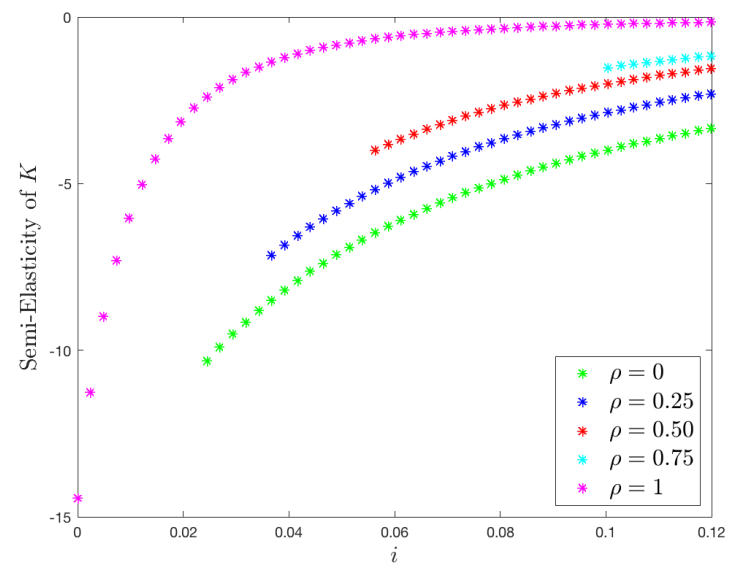

(a) Aggregate investment

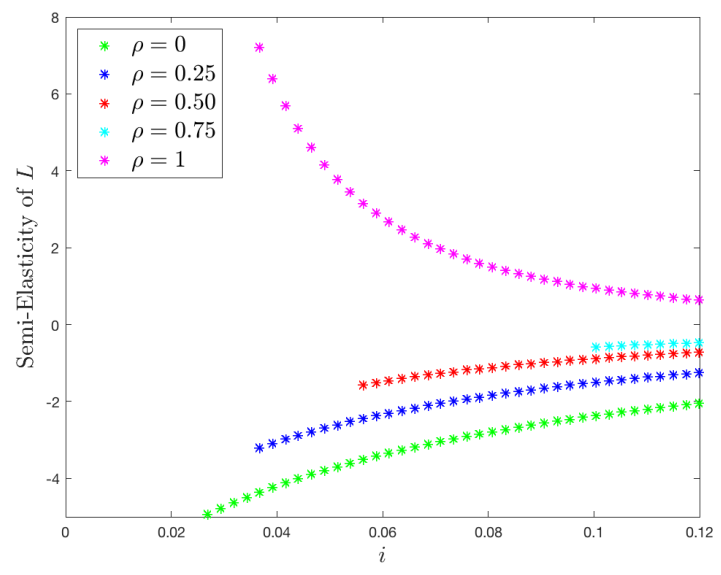

(b) Aggregate lending

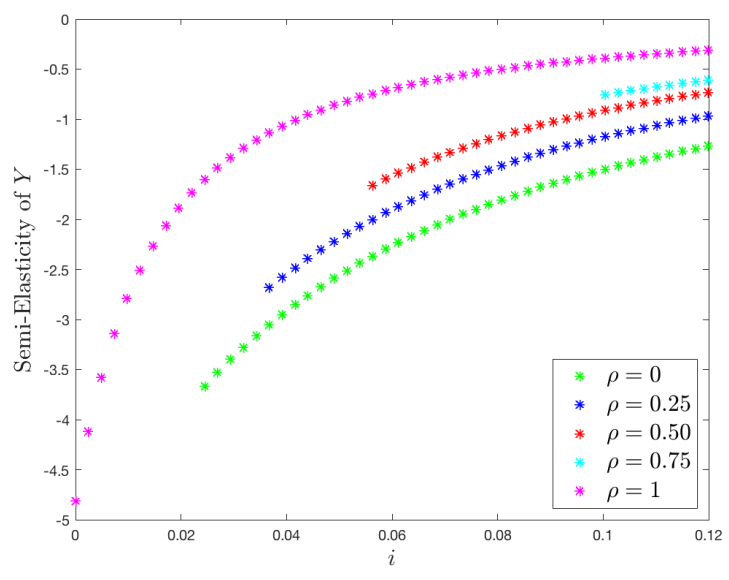

(c) Aggregate output

Figure 8: The transmission of monetary policy

\section{Access to Financial Markets}

As firms grow, they typically gain access to an extended range of funding channels. In this section, we discuss access to financial markets and its implications for optimal monetary policy. Specifically, a competitive banking sector with free bank entry in which firms meet banks with certainty and prices are taken as given. ${ }^{17}$ Analogue to the benchmark model, entrepreneurs finance $k_{I}$ internally and banks supply external financing, $k_{E}^{s}$, at a lending rate, $r^{b}$. The loan size is $k_{E}^{s}-k_{I}$, implying banks profits, $r^{b}\left(k_{E}^{s}-k_{I}\right)$, where, given the

\footnotetext{
${ }^{17}$ This section represents a limiting case of the benchmark model with $\alpha=1$ and $\theta=0$.
} 
competitive nature of the market, $r^{b}$ is taken as given. A bank solves:

$$
\begin{aligned}
\max _{k_{E}^{s}} & r^{b}\left(k_{E}^{s}-k_{I}\right) \\
\text { s.t. } & f\left(k_{E}^{s}\right)-k_{E}^{s}\left(1+r^{b}\right) \geq f\left(k_{I}\right)-k_{I},
\end{aligned}
$$

with (37) representing the entrepreneur's participation constraint. The first-order condition is given by:

$$
r^{b}+\Lambda_{1}\left[f^{\prime}\left(k_{E}^{s}\right)-1\right]=0
$$

where $\Lambda_{1}$ is the Lagrange multiplier on the entrepreneur's participation constraint, implying zero profit, $r^{b}=0$, if $k_{E}^{s}=k^{*}$. Entrepreneurs, on the other hand, choose their demand for external financing, $k_{E}^{d}$, solving:

$$
\begin{gathered}
\max _{k_{E}^{d}} f\left(k_{E}^{d}\right)-k_{E}^{d}\left(1+r^{b}\right)-\left[f\left(k_{I}\right)-k_{I}\right] \\
\text { s.t. }\left(1+r^{b}\right)\left(k_{E}^{d}-k_{I}\right) \leq \chi f\left(k_{E}^{d}\right)+\rho q_{a} a,
\end{gathered}
$$

where (40) represents the bank's participation constraint. The first-order condition is given by:

$$
f^{\prime}\left(k_{E}^{d}\right)-\left(1+r^{b}\right)+\Lambda_{2}\left[\chi f^{\prime}\left(k_{E}^{d}\right)-\left(1+r^{b}\right)\right]=0,
$$

with $\Lambda_{2}$ representing the Lagrange multiplier on the bank's participation constraint. If (40) does not bind, then $\Lambda_{2}=0$ and $f^{\prime}\left(k_{E}\right)=1$, where, given market clearing, $k_{E}^{s}=k_{E}^{d}=k^{*}$. If, however, (40) binds, then $k_{E}$ solves:

$$
k_{E}=k_{I}+\chi f\left(k_{E}\right)+\rho q_{a} a .
$$

It is straightforward to show from (42) that $\partial k_{E} / \partial \chi>0, \partial k_{E} / \partial \rho>0$, and $\partial k_{E} / \partial k_{I}>0$. Since entrepreneurs meet banks with certainty, the entrepreneur's portfolio choice in stage 2 collapses to:

$$
\max _{m^{\prime}, a^{\prime}}-\left[q_{m} / \beta-q_{m}^{\prime}\right] m^{\prime}-\left[q_{a} / \beta-q_{a}^{\prime}\right] a^{\prime}+\vartheta\left(a^{\prime}\right)+\lambda\left[f\left(k_{E}\right)-k_{E}\right]
$$


Lemma D. There exists a unique solution to (43):

$$
\begin{aligned}
q_{m} & =\beta q_{m}^{\prime}\left[1+\mathcal{L}_{m}\right], \\
q_{a} & =\beta\left[q_{a}^{\prime}\left(1+\mathcal{L}_{a}\right)+\vartheta^{\prime}(a)\right],
\end{aligned}
$$

with $\left(\mathcal{L}_{m}, \mathcal{L}_{a}\right)=(0,0)$ for $k=k^{*}$, and:

$$
\begin{aligned}
\mathcal{L}_{m} & =\lambda\left[\frac{f^{\prime}\left(k_{E}\right)-1}{1-\chi f^{\prime}\left(k_{E}\right)}\right]>0 \\
\mathcal{L}_{a} & =\lambda\left[\frac{\rho\left[f^{\prime}\left(k_{E}\right)-1\right]}{1-\chi f^{\prime}\left(k_{E}\right)}\right]>0
\end{aligned}
$$

for $k_{E}<k^{*}$. Proof in Appendix $G$.

Three cases need to be distinguished. If $k_{I}=k^{*}$, then entrepreneurs finance their entire capital accumulation using fiat money and credit cards. Since they have no need for additional means of financing, the liquidity premia for money and assets are zero, i.e., $\mathcal{L}_{m}=\mathcal{L}_{a}=0$. If $k_{I}<k^{*}$ but $k_{E}=k^{*}$, entrepreneurs are able to finance the optimal amount of capital using a combination of external and internal funding. Again, given optimality, the liquidity premia collapse to zero. Positive liquidity premia, $\mathcal{L}_{m}>0$ and $\mathcal{L}_{a}>0$, emerge in a constrained equilibrium, $k_{E}<k^{*}$, due to the demand for an additional unit of money or housing with $\mathcal{L}_{m}=\mathcal{L}_{a}$ if $\rho=1$, i.e., if fiat money and housing are perfect substitutes.

Proposition D. (Optimal monetary policy) Optimality, $k_{I}=k_{E}=k^{*}$, occurs for $i=0$ (the Friedman rule). If $i>0$, however, then $k_{I}<k_{E}<k^{*}$. Proof in Appendix $H$.

Proposition D characterizes optimal monetary policy in the presence of a competitive banking sector relying on the general equilibrium results in Lemma D. The most striking difference to the benchmark model with a decentralized banking sector is that under perfect competition, the positive range $0<i<i^{*}$ ensuring $k_{E}=k^{*}$ collapses. As a consequence, optimality can only be obtained at the Friedman rule, $i=0$. The intuition is as follows: In the presence of matching frictions, $\alpha<1$, and banks' bargaining power, $\theta>0$, fiat money has two roles: (i) it serves as an insurance against not meeting a bank, and (ii) it allows to negotiate better terms of trade when used as a downpayment. Both of these motives vanish in a competitive market. Figure 9 displays $k_{E}$ and $k_{I}$ using the parameter values defined in 
Section 7 with $\alpha=1$ and $\theta=0$, highlighting the difference to the money demand in the benchmark model represented in Figure 4.

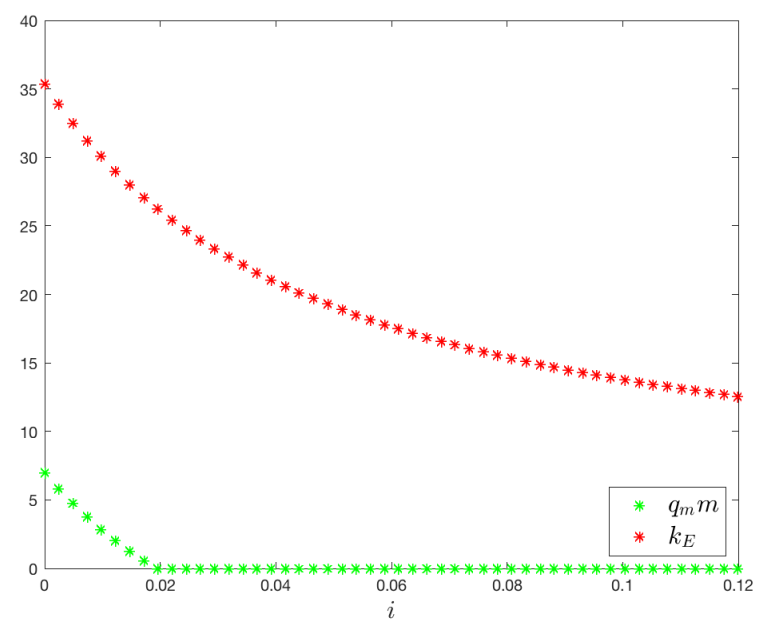

Figure 9: Internal and external finance with competitive banking sector

\section{Unconventional Policy}

We now consider an economy where monetary policy alone is not able to ensure the firstbest level of investment for entrepreneurs, i.e., $i>i^{*}$. There are many reasons this type of situation could occur. For example, housing may not be accepted as collateral, there may be a credit crunch in the banking sector, or interest rates near the Friedman rule simply may not be feasible due to inflation targeting. To go beyond conventional monetary policy, we introduce an additional policy tool by extending the baseline model to include government bonds.

There is a fixed supply, $G$, of one-period government bonds that pay the bearer one unit of the numéraire in stage 2 . We assume that bonds are partially liquid with $\chi_{g} \in[0,1]$ denoting the pledgeability parameter (analogue to $\rho$ and $\chi$ ). While bonds are always accepted by banks, with probability $\alpha_{g} \in[0,1]$, they can further be used as a direct means of payment in the competitive capital market. Let $q_{g}$ denote the price of the numéraire in terms of bonds. For brevity, we omit derivations that are straightforward given the baseline model 
and begin with an entrepreneur's portfolio choice:

$$
\begin{aligned}
\max _{m^{\prime}, a^{\prime}, g^{\prime}}-\left[q_{m} / \beta-q_{m}^{\prime}\right] m^{\prime}-\left[q_{a} / \beta-q_{a}^{\prime}\right] a^{\prime}+\vartheta\left(a^{\prime}\right)-\left[q_{g} / \beta-1\right] g^{\prime}+ \\
\lambda\left[\alpha_{g}\left[(1-\alpha) \hat{\Delta}_{I}^{e}\left(\omega^{\prime}\right)+\alpha \hat{\Delta}_{E}^{e}\left(\omega^{\prime}\right)\right]+\left(1-\alpha_{g}\right)\left[(1-\alpha) \bar{\Delta}_{I}^{e}\left(\omega^{\prime}\right)+\alpha \bar{\Delta}_{E}^{e}\left(\omega^{\prime}\right)\right]\right]
\end{aligned}
$$

where the entrepreneur's financial wealth, $\omega$, is now expanded by $\chi_{g} g$. Denoting $\hat{k}_{I}=$ $\min \left\{q_{m} m+\chi_{g} g+\bar{b}, k^{*}\right\}$ and $\hat{k}_{E}$ as the amount of capital obtained through internal and external finance when bonds are accepted by capital suppliers, the corresponding surpluses are:

$$
\begin{aligned}
& \hat{\Delta}_{I}^{e}(\omega)=\left\{\begin{array}{l}
f\left(k^{*}\right)-k^{*} \text { if } \hat{k}_{I} \geq k^{*} \\
f\left(\hat{k}_{I}\right)-\hat{k}_{I} \text { if } \hat{k}_{I}<k^{*},
\end{array}\right. \\
& \hat{\Delta}_{E}^{e}(\omega)= \begin{cases}(1-\theta)\left[f\left(k^{*}\right)-k^{*}\right]+\theta \hat{\Delta}_{I}^{e}(\omega) & \text { if } \hat{k}_{I} \geq \hat{k}_{I}^{*} \\
(1-\chi) f\left(\hat{k}_{E}\right)-\rho q_{a} a-\hat{k}_{I} & \text { if } \hat{k}_{I}<\hat{k}_{I}^{*},\end{cases}
\end{aligned}
$$

where $\hat{k}_{I}^{*}$ is the minimum amount of internally financed capital needed to obtain $k^{*}$ through a bank loan. Considering the case where capital suppliers do not accept the bonds as a means of payment, $\bar{k}_{I}=\min \left\{q_{m} m+\bar{b}, k^{*}\right\}$ and $\bar{k}_{E}$ denote the relevant quantities. The corresponding surpluses are:

$$
\begin{aligned}
& \bar{\Delta}_{I}^{e}(\omega)=\left\{\begin{array}{l}
f\left(k^{*}\right)-k^{*} \text { if } \bar{k}_{I} \geq k^{*} \\
f\left(\bar{k}_{I}\right)-\bar{k}_{I} \text { if } \bar{k}_{I}<k^{*},
\end{array}\right. \\
& \bar{\Delta}_{E}^{e}(\omega)=\left\{\begin{array}{l}
(1-\theta)\left[f\left(k^{*}\right)-k^{*}\right]+\theta \bar{\Delta}_{I}^{e}(\omega) \text { if } m \geq m^{*} \\
(1-\chi) f\left(\bar{k}_{E}\right)-\rho q_{a} a-\chi_{g} g-\bar{k}_{I} \text { if } m<m^{*},
\end{array}\right.
\end{aligned}
$$

analogue to the baseline model with an extended liquidity constraint, (15). With the surpluses in hand, we arrive at our first result.

Lemma E. Entrepreneurs obtain more externally financed capital when bonds are accepted by capital suppliers, i.e. $\hat{k}_{E} \geq \bar{k}_{E}$. Proof in Appendix I.

The intuition for Lemma $\mathrm{E}$ is the following. When government bonds are accepted by capital suppliers, entrepreneurs have a choice as to whether they spend their bonds at the 
supplier or pledge them as collateral at the bank. The results show that entrepreneurs prefer to spend their bonds at the supplier as this decreases the amount borrowed, and thus the real lending rate, $r^{b}$, by increasing their outside option. Consequentially, $\hat{k}_{E} \geq \bar{k}_{E}$.

Definition C. An equilibrium in stage 2 is a list of portfolios, terms of trade in stage 1, and aggregate balances, $\left\{[m(\cdot), a(\cdot), g(\cdot)],\left[\hat{k}_{I}(\cdot), \hat{k}_{E}(\cdot)\right],\left[\bar{k}_{I}(\cdot), \bar{k}_{E}(\cdot)\right], M, A, G\right\}$, such that:

(i) $[m, a, g]$ is a solution to (46);

(ii) $\bar{k}_{I}=\min \left\{q_{m} m+\bar{b}, k^{*}\right\}$ and $\hat{k}_{I}=\min \left\{q_{m} m+\chi_{g} g+\bar{b}, k^{*}\right\}$;

(iii) $\left[\bar{k}_{E}, \bar{\phi}, \bar{d}, \bar{y}, \bar{b}\right]$ is a solution to the bargaining game with $k_{I}=\bar{k}_{I}$;

(iv) $\left[\hat{k}_{E}, \hat{\phi}, \hat{d}, \hat{y}, \hat{b}\right]$ is a solution to the bargaining game with $k_{I}=\hat{k}_{I}$;

(v) $M^{\prime}=(1+\tau) M$ is the law of motion of the fiat money stock;

(vi) A is the total supply of housing in the economy;

(vii) $G$ is the total supply of government bonds in the economy; and

(viii) Market clearing conditions, $\int_{0}^{1} a(j) d j=A, \int_{0}^{1} m(j) d j=M$, and $\int_{0}^{1} g(j) d j=G$, hold.

Lemma F. There exists a unique solution to (46):

$$
\begin{aligned}
q_{m} & =\beta q_{m}^{\prime}\left(1+\mathcal{L}_{m}\right), \\
q_{a} & =\beta\left[q_{a}^{\prime}\left(1+\mathcal{L}_{a}\right)+\vartheta^{\prime}(a)\right], \\
q_{g} & =\beta\left(1+\mathcal{L}_{g}\right),
\end{aligned}
$$

where $\mathcal{L}_{m}, \mathcal{L}_{a}$, and $\mathcal{L}_{g}$ correspond to the liquidity premia of money, housing, and bonds, respectively. Proof in Appendix J.

The solution to the entrepreneur's portfolio choice looks similar to the baseline model. We focus on the added insights. If $i>0$, entrepreneurs hold bonds in part due to their liquidity services. If $\hat{k}_{E}=k^{*}$ and $\hat{k}_{I}<k^{*}$, bonds incur a liquidity premium because they increase the entrepreneur's outside option, $\hat{\Delta}_{I}^{e}(\omega)$, when accepted by the capital supplier. Thus, there is a strategic motive to hold bonds analogue to fiat money in the baseline model. Housing, 
however, is still priced at the fundamental value, since it does not affect the entrepreneur's outside option, and hence there is no demand for an additional unit. If $\hat{k}_{E}<k^{*}$, all three liquidity premia are positive. Proposition E characterizes optimal policy with government bonds.

Proposition E. (Optimal unconventional policy) Let $G^{*}$ denote the minimum supply of bonds that allows entrepreneurs to obtain the first-best level of investment through external finance. Comparative statics are: $\partial G^{*} / \partial \theta>0, \partial G^{*} / \partial \chi_{g}<0, \partial G^{*} / \partial \rho<0, \partial G^{*} / \partial A<0$, and $\partial G^{*} / \partial i>0$. Proof in Appendix $K$.

Proposition E establishes that there exists a minimum supply of government bonds that allows entrepreneurs to obtain the first-best level of investment through external finance. The minimal supply varies with fundamentals and monetary policy. If banks have more bargaining power, entrepreneurs face higher lending rates and therefore need more liquidity to both obtain the first-best level of investment. If bonds are more pledgeable, then each bond held by an entrepreneur generates more capital, reducing the number of bonds needed for entrepreneurs to obtain $k^{*}$. The optimal unconventional policy also depends on the state of the housing market. If there is a contraction in the housing supply, or haircuts on HELs increase, entrepreneurs are more reliant on alternative forms of liquidity, increasing the amount of bonds needed to finance $k^{*}$. Finally, an increase in the nominal interest rate reduces the amount of capital entrepreneurs obtain through internal finance, necessitating a reliance on government bonds.

Proposition F. (Optimal monetary policy with bonds) Let $i^{* *}$ denote the maximum nominal interest rate allowing entrepreneurs to obtain $\bar{k}_{E}=k^{*}$ for all $i \in\left[0, i^{* *}\right]$. We have then have $i^{* *}-i^{*}>0$ if $\chi_{g}>0$. Comparative statics involve: $\partial\left[i^{* *}-i^{*}\right] / \partial \chi_{g}>0$, $\partial\left[i^{* *}-i^{*}\right] / \partial G>0$. Proof in Appendix L.

Proposition F discusses the implications of introducing government bonds for optimal monetary policy. Drawing on our insights from the baseline model, entrepreneurs will hold enough real balances to finance $k^{*}$ through external finance if the nominal interest is within the positive range $0 \leq i \leq i^{*}$. Proposition $\mathrm{F}$ shows that the introduction of government 
bonds extends this range to $0 \leq i \leq i^{* *}$ with $i^{* *}-i^{*}>0$. As a result, entrepreneurs are able to finance $k^{*}$ for a larger range of positive nominal interest rates, as they are less reliant on fiat money when financing capital internally. The more pledgeable bonds or the larger the bond supply, the larger the difference, $\partial\left[i^{* *}-i^{*}\right] / \partial \chi_{g}>0$ and $\partial\left[i^{* *}-i^{*}\right] / \partial G>0$.

\section{Conclusion}

Motivated by the unique sources of financing and frictions faced by entrepreneurs, we developed a model of entrepreneurial finance with housing, a frictional banking sector, and monetary policy. Entrepreneurs have access to internal and external financing, where bilateral relationships in the banking sector determine the pass-through from the nominal interest rate to the bank lending rate. In doing so, the model explicitly characterizes the transmission channel of monetary policy as a function of the composition of external and internal finance, where monetary policy has a much larger impact on the entrepreneurial sector when entrepreneurs need to rely on internal finance. Our numerical examples complement the analytical results and quantify the importance of home equity loans for the entrepreneurial sector and the transmission of monetary policy to aggregate outcomes.

Once the unique frictions faced by entrepreneurs are relaxed, our framework offers further insights. If entrepreneurs have access to competitive financial markets, optimality is only achieved at the Friedman rule, as entrepreneurs no longer hold money for strategic motives. We also show that introducing partially liquid government bonds can help entrepreneurs achieve their efficient level of investment, especially if they face a high nominal interest rate or housing is not accepted as collateral. 


\section{References}

Adelino, M., Schoar, A. and Severino, F. (2015), 'House prices, collateral, and selfemployment', Journal of Financial Economics 117(2), 288-306.

Bates, T. W., Kahle, K. M. and Stulz, R. M. (2009), 'Why do u.s. firms hold so much more cash than they used to?', The Journal of Finance 64(5), 1985-2021.

Black, J., de Meza, D. and Jeffreys, D. (1996), 'House prices, the supply of collateral and the enterprise economy', Economic Journal 106(434), 60-75.

Branch, W. A., Petrosky-Nadeau, N. and Rocheteau, G. (2016), 'Financial frictions, the housing market, and unemployment', Journal of Economic Theory 164, 101-135.

Campello, M. (2015), 'Corporate liquidity management', NBER Reporter (3), 1-3.

Corradin, S. and Popov, A. (2015), 'House prices, home equity borrowing, and entrepreneurship', Review of Financial Studies 28(8), 2399-2428.

Decker, R. A. (2015), 'Collateral damage: Housing, Entrepreneurship, and Job Creation', Working Paper pp. 1-57.

Garriga, C., Manuelli, R. and Peralta-Alva, A. (2019), 'A model of price swings in the housing market', American Economic Review 109(6), 2036-2072.

Greenspan, A. and Kennedy, J. (2007), 'Sources and uses of equity extracted from homes', Federal Reserve Board Finance and Economics Discussion Series pp. 1-49.

Harding, J. P. and Rosenthal, S. S. (2017), 'Homeownership, housing capital gains and selfemployment', Journal of Urban Economics 99, 120-135.

He, C., Wright, R. and Zhu, Y. (2015), 'Housing and liquidity', Review of Economic Dynamics 18(3), 435-455.

Iacoviello, M. (2011), 'Housing wealth and consumption', Board of Governors International Finance Discussion Papers pp. 1-15.

Jensen, T. L., Leth-Petersen, S. and Nanda, R. (2014), 'Housing collateral, credit constraints and entrepreneurship - evidence from a mortgage reform', NBER Working Paper 20583 pp. 1-46. 
Justiniano, A., Primiceri, G. E. and Tambalotti, A. (2015), 'Credit supply and the housing boom', Working Paper.

Kiyotaki, N. and Moore, J. (1997), 'Credit cycles', Journal of Political Economy 105(2), 211248.

Lagos, R., Rocheteau, G. and Wright, R. (2017), 'Liquidity: A New Monetarist perspective', Journal of Economic Literature 55(2), 371-440.

Lagos, R. and Wright, R. (2005), 'A unified framework for monetary theory and policy analysis', Journal of Political Economy 113(3), 463-484.

Lim, T. (2018), 'Housing as collateral, financial constraints, and small businesses', Review of Economic Dynamics 30, 68-85.

Liu, Z., Wang, P. and Zha, T. (2013), 'Land-price dynamics and macroeconomic fluctuations', Econometrica 81(3), 1147-1184.

Mora, N. (2014), 'The weakened transmission of monetary policy to consumer loan rates', Federal Reserve Bank of Kansas City Economic Review pp. 93-117.

Rocheteau, G. and Nosal, E. (2017), Money, Payments, and Liquidity, 2nd edn, MIT Press.

Rocheteau, G., Wright, R. and Zhang, C. (2018), 'Corporate finance and monetary policy', American Economic Review 108(4-5), 1147-86.

Sánchez, J. M. and Yurdagul, E. (2013), 'Why are U.S. firms holding so much cash? an exploration of cross-sectional variation', Federal Reserve Bank of St. Louis Review 95(4), 293325.

Schmalz, M., Sraer, D. A. and Thesmar, D. (2017), 'Housing collateral and entrepreneurship', Journal of Finance 72(1), 99-132.

Silva, M. (2019), 'Corporate finance, monetary policy, and aggregate demand', Journal of Economic Dynamics \& Control 102, 1-28.

Wasmer, E. and Weil, P. (2004), 'The macroeconomics of labor and credit market imperfections', The American Economic Review 94(4), 944-963. 


\section{Appendix: Proofs}

\section{A. Proof of Lemma A}

We show uniqueness in a constrained equilibrium, as $k_{E}=k^{*}$ in an unconstrained equilibrium. We rearrange (22) as:

$$
\theta f\left(k_{E}\right)+(1-\theta) k_{E}-\theta \Delta_{I}^{e}(\omega)=\chi f\left(k_{E}\right)+\rho q_{a} a+q_{m} m
$$

If $k_{E}=0$, the left hand side of (54) is less than zero and the right hand side is greater than zero. As $k_{E} \rightarrow \infty$, the left hand side increases at rate $\theta f^{\prime}\left(k_{E}\right)+(1-\theta)$ and the right hand side increases at rate $\chi f^{\prime}\left(k_{E}\right)$. The left hand side of (54) will eventually surpass the right hand side if $1-\theta>(\chi-\theta) f^{\prime}\left(k_{E}\right)$, which is true for some $k_{E}>0$, as $f^{\prime}\left(k_{E}\right) \rightarrow 0$ as $k_{E} \rightarrow \infty$. Thus, there exists a unique $k_{E}>0$ that satisfies (22).

Second, we establish that $k_{E} \in\left[\underline{k}_{E}, k^{*}\right]$ where $\chi f^{\prime}\left(\underline{k}_{E}\right)=1$. Consider the entrepreneur's binding liquidity constraint, (15). Solving for the bank's surplus, $\phi$, gives

$$
\phi=\chi f\left(k_{E}\right)-k_{E}+\rho q_{a} a+k_{I}
$$

From (55), the bank's surplus is maximized at $\underline{k}_{E}$. Suppose that $k_{E}<\underline{k}_{E}$. A Pareto improve-

ment can be made by increasing $k_{E}$ to $\underline{k}_{E}$, as both the surplus of the bank and entrepreneur are strictly larger at $\underline{k}_{E}$. Thus, $\underline{k}_{E}$ is a lower bound on capital acquired through bank credit.

\section{B. Proof of Lemma B}

Consider the case where $m<m^{*}$. From (21), the real lending rate is given by

$$
r^{b}=\frac{\theta\left[f\left(k_{E}\right)-k_{E}-\Delta_{I}^{e}(\omega)\right]}{k_{E}-k_{I}} .
$$

Now consider when $m \geq m^{*}$. From $(20), r^{b}$ is given by (56) with $k_{E}=k^{*}$.

\section{Proof of Lemma C}


Taking the first-order condition of $(24)$ with respect to $m^{\prime}$ gives

$$
q_{m}=\beta\left\{q_{m}^{\prime}+\lambda\left[\alpha \frac{\partial \Delta_{E}^{e}\left(\omega^{\prime}\right)}{\partial m^{\prime}}+(1-\alpha) \frac{\partial \Delta_{I}^{e}\left(\omega^{\prime}\right)}{\partial m^{\prime}}\right]\right\}
$$

where

$$
\frac{\partial \Delta_{I}^{e}\left(\omega^{\prime}\right)}{\partial m^{\prime}}=q_{m}^{\prime}\left[f^{\prime}\left(k_{I}\right)-1\right]
$$

and

$$
\frac{\partial \Delta_{E}^{e}\left(\omega^{\prime}\right)}{\partial m^{\prime}}= \begin{cases}\theta q_{m}^{\prime}\left[f^{\prime}\left(k_{I}\right)-1\right] & \text { if } k_{E} \geq k^{*} \\ q_{m}^{\prime}\left[\frac{(1-\chi) f^{\prime}\left(k_{E}\right)\left[1+\theta\left(f^{\prime}\left(k_{I}\right)-1\right)\right]}{(1-\theta)-(\chi-\theta) f^{\prime}\left(k_{E}\right)}-1\right] & \text { if } \quad k_{E}<k^{*} .\end{cases}
$$

Combining (58) and (59) gives $\mathcal{L}_{m}$. The first-order condition of (24) with respect to $a^{\prime}$ is

$$
q_{a}=\beta\left\{q_{a}^{\prime}+\vartheta^{\prime}\left(a^{\prime}\right)+\lambda \alpha \frac{\partial \Delta_{E}^{e}\left(\omega^{\prime}\right)}{\partial a^{\prime}}\right\}
$$

where

$$
\frac{\partial \Delta_{E}^{e}\left(\omega^{\prime}\right)}{\partial a^{\prime}}=\left\{\begin{array}{lll}
0 & \text { if } \quad k_{E} \geq k^{*} \\
\rho q_{a}^{\prime}\left[\frac{(1-\chi) f^{\prime}\left(k_{E}\right)}{(1-\theta)+(\theta-\chi) f^{\prime}\left(k_{E}\right)}\right] & \text { if } \quad k_{E}<k^{*} .
\end{array}\right.
$$

Substituting (61) into (60) and rearranging gives $\mathcal{L}_{a}$.

\section{Proof of Proposition A}

The portfolio choice of money and housing can be written as

$$
\max _{k_{I}, a^{\prime}}\left\{-i q_{m} m^{\prime}-[1 / \beta-1] q_{a} a^{\prime}+\vartheta\left(a^{\prime}\right)+\lambda\left[\alpha \Delta_{E}^{e}(\omega)+(1-\alpha) \Delta_{I}^{e}(\omega)\right]\right\}
$$

where $i \equiv \gamma / \beta-1$. If $i=0$, then $k_{I}=k_{E}=k^{*}$ so that $\partial \Delta_{E}^{e}\left(\omega^{\prime}\right) / \partial k_{I}=\partial \Delta_{I}^{e}\left(\omega^{\prime}\right) / \partial k_{I}=0$. The first-order condition of (62) with respect to $q_{m} m$ gives

$$
i=\lambda[1-\alpha(1-\theta)]\left[f^{\prime}\left(k_{I}\right)-1\right]
$$

for $0<i \leq i^{*}$. It follows that $k_{I}<k^{*}$ to satisfy (63) and that $\partial k_{I} / \partial i<0$. If $i>i^{*}, k_{I}$ is determined by

$$
i=\lambda \alpha\left[\frac{(1-\chi) f^{\prime}\left(k_{E}\right)\left[1+\theta\left(f^{\prime}\left(k_{I}\right)-1\right)\right]}{(1-\theta)-(\chi-\theta) f^{\prime}\left(k_{E}\right)}-1\right]+\lambda(1-\alpha)\left[f^{\prime}\left(k_{I}\right)-1\right] .
$$


If $i$ increases, (64) is satisfied if and only if the right hand side increases. Since $f^{\prime}\left(k_{I}\right)$ is decreasing in $k_{I}$, the first and the second term on the right hand side are decreasing in $k_{I}$. Thus, $\frac{\partial m}{\partial i}<0$. We use this result to show that $\frac{\partial k_{E}}{\partial i}<0$ and $k_{E}<k^{*}$ for $m<m^{*}$. Differentiation of the entrepreneur's liquidity constraint gives

$$
\frac{\partial k_{E}}{\partial i}=\frac{\left[\theta f^{\prime}\left(k_{I}\right)+(1-\theta)\right] \frac{\partial k_{I}}{\partial i}}{(\theta-\chi) f^{\prime}\left(k_{E}\right)+(1-\theta)}<0,
$$

as $\chi f^{\prime}\left(k_{E}\right)<1$. It follows that $k_{E}<k^{*}$ for $i>i^{*}$.

Next, we show that $\frac{\partial a}{\partial i} \geq 0$. If $m \geq m^{*}$, then housing is priced at it's fundamental value and thus $\frac{\partial a}{\partial i}=0$. In the case where $m<m^{*}$, the price of housing is given by

$$
q_{a}=\frac{\beta \vartheta^{\prime}(a)}{1-\beta\left\{1-\lambda \alpha \rho\left[\frac{(1-\chi) f^{\prime}\left(k_{E}\right)}{(1-\theta)-(\chi-\theta) f^{\prime}\left(k_{E}\right)}-1\right]\right\}}
$$

If $i$ increases, $k_{E}$ will decrease. From (66), $q_{a}$ will increase following a decline in $k_{E}$ and therefore $\frac{\partial a}{\partial i}>0$ when $m<m^{*}$.

To determine $\partial i^{*} / \partial \chi>0$ and $\partial i^{*} / \partial \rho>0$, we rewrite (22) and substitute $k_{E}=k^{*}$ (since $\left.i=i^{*}\right)$ to get:

$$
\theta f(\tilde{k})+(1-\theta) \tilde{k}=(\theta-\chi) f\left(k^{*}\right)+(1-\theta) k^{*}-\rho q_{a} a
$$

where $\tilde{k}$ is the amount of internally financed capital to acquire $k^{*}$ through a bank loan at $i=i^{*}$. Suppose that $\rho$ or $\chi$ increases. In order for (67) to hold with equality and maintain $k^{*}, \tilde{k}$ must decrease. Now consider (63). Rearranging and setting $i=i^{*}$ gives

$$
f^{\prime}(\tilde{k})=\frac{i^{*}}{\lambda[1-\alpha(1-\theta)]} .
$$

It follows that $i^{*}$ increases if $\tilde{k}$ decreases, $\partial i^{*} / \partial \chi>0$, and $\partial i^{*} / \partial \rho>0$.

\section{E. Proof of Proposition B}

A second-order approximation of $f\left(k_{I}\right)-k_{I}$ around $k^{*}$ is given by:

$$
f\left(k_{I}\right)-k_{I} \approx f\left(k^{*}\right)-k^{*}+\frac{f^{\prime \prime}\left(k^{*}\right)}{2}\left(k_{I}-k^{*}\right)^{2} .
$$


Recall that $\Delta_{I}^{e}(\omega)=f\left(k_{I}\right)-k_{I}$. Substituting (69) into (23) gives:

$$
r^{b} \approx \frac{\theta\left[f^{\prime \prime}\left(k^{*}\right)\left(k_{I}-k^{*}\right)\right]}{2} .
$$

Next, a first-order approximation of $f^{\prime}\left(k_{I}\right)$ around $k^{*}$ is given by:

$$
f^{\prime}\left(k_{I}\right) \approx 1+f^{\prime \prime}\left(k^{*}\right)\left(k_{I}-k^{*}\right)
$$

Substituting $f^{\prime \prime}\left(k^{*}\right)\left(k_{I}-k^{*}\right) \approx f^{\prime}\left(k_{I}\right)-1$ into (63) gives:

$$
f^{\prime \prime}\left(k^{*}\right)\left(k_{I}-k^{*}\right) \approx \frac{i}{\lambda[1-\alpha(1-\theta)]} .
$$

Substituting (72) into (70) gives (30).

Last but not least, to determine comparative statics, the strength of the pass-through is given by

$$
\frac{\partial r^{b}}{\partial i}=\frac{\theta}{2 \lambda[1-\alpha(1-\theta)]},
$$

which is decreasing (increasing) in $\lambda(\alpha)$ and independent of $\chi$ and $\rho$. Rearranging (73) gives

$$
\frac{\partial r^{b}}{\partial i}=\frac{1}{2 \lambda\left(\frac{1}{\theta}(1-\alpha)+\alpha\right)}
$$

which is increasing in $\theta$.

\section{F. Proof of Proposition C}

For $i \leq i^{*}$, the economy is in an unconstrained equilibrium (region $A$ in Figure 5) and we refer to the derivations in Appendix N. From equations (99) and (32):

$$
\begin{aligned}
\frac{\partial k_{I}}{\partial i} & =\frac{1}{\lambda f^{\prime \prime}\left(k^{*}\right)(1-\alpha(1-\theta))}<0, \\
\frac{\partial L}{\partial i} & =-\frac{\alpha}{f^{\prime \prime}\left(k^{*}\right)(1-\alpha(1-\theta))}>0
\end{aligned}
$$

and $\partial k_{E} / \partial i=0$ as $k_{E}=k^{*}$. For $i>i^{*}$, the economy is in a constrained equilibrium. From 
equations (33)-(34),

$$
\begin{aligned}
\frac{\partial k_{I}}{\partial i} & =-\frac{1-\mathcal{O}}{D}<0 \\
\frac{\partial k_{E}}{\partial i} & =-\frac{1}{D}<0 \\
\frac{\partial L}{\partial i} & =-\lambda \alpha \frac{\mathcal{O}}{D} \gtrless 0,
\end{aligned}
$$

as $D>0$ and $1-\mathcal{O}>0$. We can see that $\partial k_{E} / \partial i<\partial k_{I} / \partial i<0$ and $\partial L / \partial i<0$ if $\mathcal{O}>0$. From (35), $\mathcal{O}>0$ if $\chi$ is large relative to $\rho$, corresponding to region $C$ in Figure 5 . If $\mathcal{O}<0$, then $\partial k_{I} / \partial i<\partial k_{E} / \partial i<0$ and $\partial L / \partial i>0$. From (35), $\mathcal{O}<0$ is $\rho$ is large relative to $\chi$ (region $B$ in Figure 5).

Consider $\partial\left|\partial k_{E} / \partial i\right| / \partial \rho$. From equation (106),

$$
\frac{\partial k_{E}}{\partial i}=-\frac{1}{D}<0
$$

as $D>0$. In order to show that $\left|\partial k_{E} / \partial i\right|$ is decreasing in $\rho$, we first establish that $\frac{\partial D}{\partial \rho}>0$. From equation (107),

$$
\begin{aligned}
\frac{\partial D}{\partial \rho} & =-\lambda(1-\alpha)(1-\chi) f^{\prime \prime \prime}(\tilde{k}) \frac{\partial \tilde{k}}{\partial \rho}+\lambda(1-\alpha) f^{\prime \prime \prime}(\tilde{k}) \frac{\partial \tilde{k}}{\partial \rho}\left(\frac{\beta \rho}{1-\beta}\right)^{2}\left[\frac{\alpha \lambda a \vartheta^{\prime}(a) f^{\prime \prime}\left(k^{*}\right)}{1-\chi}\right] \\
& +2 \lambda(1-\alpha) f^{\prime \prime}(\tilde{k})\left(\frac{\beta \rho}{1-\beta}\right)\left(\frac{\beta}{1-\beta}\right)\left[\frac{\alpha \lambda a \vartheta^{\prime}(a) f^{\prime \prime}\left(k^{*}\right)}{1-\chi}\right]>0,
\end{aligned}
$$

as $f^{\prime \prime \prime}(\tilde{k})>0, f^{\prime \prime}\left(k^{*}\right)<0$ and $\partial \tilde{k} / \partial \rho=-\frac{\beta a \vartheta^{\prime}(a)}{1-\beta}<0$. Thus, $\partial\left|\partial k_{E} / \partial i\right| / \partial \rho<0$.

\section{G. Proof of Lemma D}

Taking the first-order condition of (43) with respect to m' gives:

$$
q_{m}=\beta\left\{q_{m}^{\prime}+\lambda\left[f^{\prime}\left(k_{E}\right)-1\right] \frac{\partial k_{E}}{\partial m}\right\},
$$

where, given (42):

$$
\frac{\partial k_{E}}{\partial m}=\frac{q_{m}^{\prime}}{1-\chi f^{\prime}\left(k_{E}\right)},
$$

if $k_{E}<k^{*}$ and zero otherwise. Combining $(\mathrm{G})$ and $(\mathrm{G})$ gives $\mathcal{L}_{m}$ in (44). The first-order 
condition of (43) with respect to $a^{\prime}$ is:

$$
q_{a}=\beta\left\{q_{a}^{\prime}+\vartheta^{\prime}\left(a^{\prime}\right)+\lambda\left[f^{\prime}\left(k_{E}\right)-1\right] \frac{\partial k_{E}}{\partial a}\right\}
$$

where given (42):

$$
\frac{\partial k_{E}}{\partial a}=\frac{q_{a}^{\prime} \rho}{1-\chi f^{\prime}\left(k_{E}\right)},
$$

if $k_{E}<k^{*}$ and zero otherwise. Substituting (83) into (82) and rearranging gives $\mathcal{L}_{a}$ in (45).

\section{H. Proof of Proposition D}

Rearranging the liquidity premium for money, (44), in Proposition D gives:

$$
i=\lambda\left[\frac{f^{\prime}\left(k_{E}\right)-1}{1-\chi f^{\prime}\left(k_{E}\right)}\right],
$$

indicating $k_{I}<k_{E}<k^{*}$ for $i>0$.

\section{Proof of Lemma $\mathrm{E}$}

Consider the entrepreneur's liquidity constraint when $\hat{k}_{E}<k^{*}$ :

$$
\hat{k}_{I}+\theta\left[f\left(\hat{k}_{I}\right)-\hat{k}_{I}\right]=(\theta-\chi) f\left(\hat{k}_{E}\right)+(1-\theta)-\rho q_{a} a-\chi_{g} q_{g}(1-x) g,
$$

where $\hat{k}_{I}=q_{m} m+x g+\bar{b}$ and $x \in[0,1]$ is the fraction of bonds the entrepreneur spends directly at the capital supplier. From (85),

$$
\frac{\partial \hat{k}_{E}}{\partial x}=\frac{g\left(1-\chi_{g}+\theta\left[f^{\prime}\left(\hat{k}_{I}\right)-1\right]\right)}{(1-\theta)+(\theta-\chi) f^{\prime}\left(\hat{k}_{E}\right)} .
$$

It follows that $\partial \hat{k}_{E} / \partial x>0$ as $f^{\prime}\left(\hat{k}_{I}\right)>1$ for all $\hat{k}_{I}<k^{*}$ and that entrepreneurs obtain more external financing by using their bonds at the capital supplier rather than pledging them at the bank.

\section{J. Proof of Lemma F}


Taking the first-order condition of (46) with respect to $m^{\prime}$ gives

$$
\begin{aligned}
q_{m}=\beta\left\{q_{m}^{\prime}+\lambda\left[\alpha_{g}\left(\alpha \frac{\partial \hat{\Delta}_{E}^{e}\left(\omega^{\prime}\right)}{\partial m^{\prime}}+(1-\alpha) \frac{\partial \hat{\Delta}_{I}^{e}\left(\omega^{\prime}\right)}{\partial m^{\prime}}\right)+\right.\right. & \\
& \left.\left.\left(1-\alpha_{g}\right)\left(\alpha \frac{\partial \bar{\Delta}_{E}^{e}\left(\omega^{\prime}\right)}{\partial m^{\prime}}+(1-\alpha) \frac{\partial \bar{\Delta}_{I}^{e}\left(\omega^{\prime}\right)}{\partial m^{\prime}}\right)\right]\right\}
\end{aligned}
$$

where $\frac{\partial \bar{\Delta}_{I}^{e}\left(\omega^{\prime}\right)}{\partial m^{\prime}}$ and $\frac{\partial \bar{\Delta}_{E}^{e}\left(\omega^{\prime}\right)}{\partial m^{\prime}}$ are given by $(58)-(59)$,

$$
\frac{\partial \hat{\Delta}_{I}^{e}\left(\omega^{\prime}\right)}{\partial m^{\prime}}=q_{m}^{\prime}\left[f^{\prime}\left(\hat{k}_{I}\right)-1\right]
$$

and

$$
\frac{\partial \hat{\Delta}_{E}^{e}\left(\omega^{\prime}\right)}{\partial m^{\prime}}= \begin{cases}\theta q_{m}^{\prime}\left[f^{\prime}\left(\hat{k}_{I}\right)-1\right] & \text { if } \quad \hat{k}_{E} \geq k^{*} \\ q_{m}^{\prime}\left[\frac{(1-\chi) f^{\prime}\left(\hat{k}_{E}\right)\left[1+\theta\left(f^{\prime}\left(\hat{k}_{I}\right)-1\right)\right]}{(1-\theta)-(\chi-\theta) f^{\prime}\left(\hat{k}_{E}\right)}-1\right] & \text { if } \quad \hat{k}_{E}<k^{*}\end{cases}
$$

The first-order condition of (46) with respect to $a^{\prime}$ is given by

$$
q_{a}=\beta\left\{q_{a}^{\prime}+\vartheta^{\prime}\left(a^{\prime}\right)+\lambda \alpha\left[\alpha_{g} \frac{\partial \hat{\Delta}_{E}^{e}\left(\omega^{\prime}\right)}{\partial a^{\prime}}+\left(1-\alpha_{g}\right) \frac{\partial \bar{\Delta}_{E}^{e}\left(\omega^{\prime}\right)}{\partial a^{\prime}}\right]\right\}
$$

where $\frac{\partial \bar{\Delta}_{E}^{e}\left(\omega^{\prime}\right)}{\partial a^{\prime}}$ is given by $(61)$ and

$$
\frac{\partial \hat{\Delta}_{E}^{e}\left(\omega^{\prime}\right)}{\partial a^{\prime}}= \begin{cases}0 & \text { if } \hat{k}_{E} \geq k^{*} \\ \rho q_{a}^{\prime}\left[\frac{(1-\chi) f^{\prime}\left(\hat{k}_{E}\right)}{(1-\theta)+(\theta-\chi) f^{\prime}\left(\hat{k}_{E}\right)}\right] & \text { if } \quad \hat{k}_{E}<k^{*}\end{cases}
$$

Finally, the first-order condition of (46) with respect to $g^{\prime}$ is given by

$$
q_{g}=\beta\left\{1+\lambda\left[\alpha_{g}\left(\alpha \frac{\partial \hat{\Delta}_{E}^{e}\left(\omega^{\prime}\right)}{\partial g^{\prime}}+(1-\alpha) \frac{\partial \hat{\Delta}_{I}^{e}\left(\omega^{\prime}\right)}{\partial g^{\prime}}\right)+\left(1-\alpha_{g}\right) \alpha \frac{\partial \bar{\Delta}_{E}^{e}\left(\omega^{\prime}\right)}{\partial g^{\prime}}\right]\right\}
$$

where

$$
\begin{gathered}
\frac{\partial \hat{\Delta}_{I}^{e}\left(\omega^{\prime}\right)}{\partial g^{\prime}}=\chi_{g}\left[f^{\prime}\left(\hat{k}_{I}\right)-1\right], \\
\frac{\partial \hat{\Delta}_{E}^{e}\left(\omega^{\prime}\right)}{\partial g^{\prime}}= \begin{cases}\theta \chi_{g}\left[f^{\prime}\left(\hat{k}_{I}\right)-1\right] & \text { if } \hat{k}_{E} \geq k^{*}, \\
\chi_{g}\left[\frac{(1-\chi) f^{\prime}\left(\hat{k}_{E}\right)\left[1+\theta\left(f^{\prime}\left(\hat{k}_{I}\right)-1\right)\right]}{(1-\theta)-(\chi-\theta) f^{\prime}\left(\hat{k}_{E}\right)}-1\right] & \text { if } \quad \hat{k}_{E}<k^{*},\end{cases}
\end{gathered}
$$




$$
\frac{\partial \bar{\Delta}_{E}^{e}\left(\omega^{\prime}\right)}{\partial g^{\prime}}=\left\{\begin{array}{lll}
0 & \text { if } & \bar{k}_{E} \geq k^{*}, \\
\chi_{g}\left[\frac{(1-\chi) f^{\prime}\left(\bar{k}_{E}\right)}{(1-\theta)+(\theta-\chi) f^{\prime}\left(\bar{k}_{E}\right)}\right] & \text { if } & \bar{k}_{E}<k^{*} .
\end{array}\right.
$$

The liquidity premia, $\mathcal{L}_{m}, \mathcal{L}_{a}$, and $\mathcal{L}_{g}$, are then given by the terms multiplied by $\lambda$ in equations (87), (90), and (92).

\section{K. Proof of Proposition E}

Consider a constrained equilibrium where $\hat{k}_{I}<k^{*}$ and $k_{I}<k^{*}$. Entrepreneurs will always obtain the first-best level of investment through external finance if they can obtain $k^{*}$ when bonds are not accepted by capital suppliers, as $\bar{k}_{E} \leq \hat{k}_{E}$ from the proof of Lemma E. For a given level of internally financed capital, $k_{I}$, the smallest amount of bond holdings to obtain $k^{*}$ is the supply of bonds which makes the entrepreneur's liquidity constraint bind at $\bar{k}_{E}=k^{*}$ :

$$
k_{I}+\theta\left[f\left(k_{I}\right)-k_{I}\right]=(\theta-\chi) f\left(k^{*}\right)+(1-\theta) k^{*}-\frac{\rho A \vartheta^{\prime}(A)}{1-\beta}-\chi_{g} G^{*} .
$$

It is then straightforward to solve for $G^{*}$ and obtain the comparative statics.

\section{Proof of Proposition F}

Denote $z^{* *}$ as the minimal level of real balances an entrepreneur must hold to obtain $\bar{k}_{E}=k^{*}$. By definition, the entrepreneur's liquidity constraint with the bank binds at $z^{* *}$ and with $\bar{k}_{E}=k^{*}$ and is thus determined by

$$
k_{I}^{*}+\theta\left[f\left(k_{I}^{*}\right)-k_{I}^{*}\right]=(\theta-\chi) f\left(k^{*}\right)+(1-\theta) k^{*}-\frac{\rho A \vartheta^{\prime}(A)}{1-\beta}-\chi_{g} G .
$$

Note that the right hand side of $(97)$ is decreasing in $\chi_{g}$ and $G$. It follows that $z^{* *}$ will decrease to ensure that (97) is satisfied after a change in any of these parameters, meaning that a smaller amount of real balances are needed to obtain $\bar{k}_{E}=k^{*}$. As demand for real balances are decreasing in the nominal interest rate, it follows that entrepreneurs will hold at least $z^{* *}$ at even higher levels of the nominal interest rate, increasing $i^{* *}$. It is also clear that $i^{* *}$ converges to $i^{*}$ as $\chi_{g} \rightarrow 0$, as the entrepreneur's liquidity constraint becomes the same as when there are no bonds in the model, giving $i^{* *}-i^{*}>0$ for $\chi_{g}>0$. 


\section{Appendix: Supplementary Material}

\section{Data sources and construction}

In the numerical examples of Section 7, our measure for the nominal interest (bank lending) rate was the 3-month T-bill secondary market (bank prime) rate. Our measure of $\alpha$, the probability to receive a bank loan, follows from Rocheteau et al. (2018) who found that between $78-90 \%$ of respondents in the 2003 Survey of Small Business Finances had their most recent loan application approved. To calculate the pledgeability of output, we first calculated the average of (i) total loans to non-financial non-corporate businesses and (ii) total loans to non-financial non-corporate businesses net total home equity loans. We then divide the amount of loans to non-financial non-corporate businesses by total assets among non-financial non-corporate businesses. Both the data on loans and assets among non-financial non-corporate businesses come from the Flow of Funds Accounts, where we use quantities from Q4 in each year.

Our calculation of the pledgeability of housing, $\rho$, and maximum amount of unsecured credit, $\bar{b}$, draws on data from (i) the Federal Reserve Bank of New York's Quarterly Report on Household Debt and Credit and (ii) Average Sales Price of Houses Sold for the United States from the Federal Reserve Bank of St. Louis' FRED data base (series ASPUS). To calculate $\rho$, we first compute the average Home Equity Revolving Limit by dividing the total amount of Home Equity Revolving Limit by the number of Home Equity accounts between 2003:Q1-2016:Q4 using the FRBNY data. We then compute the ratio of the average home equity limit to the average sale price of U.S. homes. To calculate $\bar{b}$, we compute the average credit limit by dividing the aggregate credit card limit by the number of credit card accounts in the FRBNY data between 2003:Q1-2016:Q4. We then compute the average ratio of credit limits to home equity loan limits and choose $\bar{b}$ so the ratio of the maximum amount of unsecured credit relative to the maximum home equity loan in the model corresponds to the same ratio in the data.

Last but not least, we estimated the probability of receiving an investment opportunity, $\lambda$, by using data from the SCF between 2001-2016. Specifically, we calculated the fraction of respondents who started or acquired their business within the last year. ${ }^{18}$

\footnotetext{
${ }^{18}$ Our calculation uses sample weights provided by the SCF.
} 
N. Derivation of Equations (31)-(35)

Consider an unconstrained equilibrium. Solving for $k_{I}-k^{*}$ from (70) gives:

$$
k_{I}-k^{*} \approx \frac{2 r^{b}}{\theta f^{\prime \prime}\left(k^{*}\right)}
$$

Substituting (30) into (98) gives

$$
k_{I} \approx k^{*}+\frac{i}{\lambda f^{\prime \prime}\left(k^{*}\right)[1-\alpha(1-\theta)]}
$$

Plugging $k_{I}$ from (99) and $k_{E} \approx k^{*}$ into $K \equiv \lambda\left[(1-\alpha) k_{I}+\alpha k_{E}\right]$ and $L \equiv \lambda \alpha\left(k_{E}-k_{I}\right)$ gives (31) and (32).

Now consider a constrained equilibrium with $\theta=0$. The triple $\left(k_{E}, k_{I}, q_{a}\right)$ is determined by equations (22), (64), and (66):

$$
\begin{aligned}
k_{E} & =\chi f\left(k_{E}\right)+\rho q_{a} a+k_{I}, \\
i & =\lambda\left[\alpha \frac{f^{\prime}\left(k_{E}\right)-1}{1-\chi f^{\prime}\left(k_{E}\right)}+(1-\alpha)\left[f^{\prime}\left(k_{I}\right)-1\right]\right], \\
q_{a} & =\frac{\left(1-\chi f^{\prime}\left(k_{E}\right)\right) \beta \vartheta^{\prime}(a)}{(1-\beta)\left(1-\chi f^{\prime}\left(k_{E}\right)\right)-\beta \alpha \lambda \rho\left(f^{\prime}\left(k_{E}\right)-1\right)} .
\end{aligned}
$$

Substituting (102) into (100) gives:

$$
k_{E}=\chi f\left(k_{E}\right)+\frac{\rho a\left(1-\chi f^{\prime}\left(k_{E}\right)\right) \beta \vartheta^{\prime}(a)}{(1-\beta)\left(1-\chi f^{\prime}\left(k_{E}\right)\right)-\beta \alpha \lambda \rho\left(f^{\prime}\left(k_{E}\right)-1\right)}+k_{I} .
$$

A first-order approximation of (103) and (101) in the neighborhood $\left(k_{I}, k_{E}\right)=\left(\tilde{k}, k^{*}\right)$ gives:

$$
\begin{gathered}
\left(1-\chi-\left(\frac{\beta \rho}{1-\beta}\right)^{2}\left[\frac{\alpha \lambda a \vartheta^{\prime}(a) f^{\prime \prime}\left(k^{*}\right)}{1-\chi}\right]\right)\left(k_{E}-k^{*}\right) \approx\left(k_{I}-\tilde{k}\right), \\
\lambda(1-\alpha) f^{\prime \prime}(\tilde{k})\left(k_{I}-\tilde{k}\right)+\lambda \alpha \frac{f^{\prime \prime}\left(k^{*}\right)}{1-\chi}\left(k_{E}-k^{*}\right) \approx i-i^{*} .
\end{gathered}
$$


Solving (104) and (105) for $\left(k_{I}-\tilde{k}\right)$ and $\left(k_{E}-k^{*}\right)$ gives:

$$
\left(\begin{array}{c}
k_{I}-\tilde{k} \\
k_{E}-k^{*}
\end{array}\right)=\frac{1}{D}\left(\begin{array}{cc}
\frac{\lambda \alpha f^{\prime \prime}\left(k^{*}\right)}{1-\chi} & -(1-\chi)+\left(\frac{\beta \rho}{1-\beta}\right)^{2}\left[\frac{\alpha \lambda a \vartheta^{\prime}(a) f^{\prime \prime}\left(k^{*}\right)}{1-\chi}\right] \\
-\lambda(1-\alpha) f^{\prime \prime}(\tilde{k}) & -1
\end{array}\right)\left(\begin{array}{c}
0 \\
i-i^{*}
\end{array}\right),
$$

where

$$
D=-\frac{\lambda \alpha f^{\prime \prime}\left(k^{*}\right)}{1-\chi}-\lambda(1-\alpha) f^{\prime \prime}(\tilde{k})\left((1-\chi)-\left(\frac{\beta \rho}{1-\beta}\right)^{2}\left[\frac{\alpha \lambda a \vartheta^{\prime}(a) f^{\prime \prime}\left(k^{*}\right)}{1-\chi}\right]\right)>0,
$$

gives $k_{I}$ and $k_{E}$. Finally, using $L \equiv \lambda \alpha\left(k_{E}-k_{I}\right)$ and substituting $k_{I}$ and $k_{E}$ gives (34). 